\title{
El sistema político salvadoreño a finales de 1995 Sondeo de opinión pública
}

\author{
Instituto Universitario de Opinión Pública
}

\section{Resumen}

Entre el 21 y el 28 de octubre de 1995, el IUDOP realizó una encuesta de opinión pública con una muestra de 1,222 adultos, representativa de la población total de El Salvador y con un margen de error del 4 por ciento. El sondeo, diseñado para recoger la opinión de los ciudadanos sobre el contexto político salvadoreño y para adelantar las preferencias de los salvadoreños por las opciones políticas, mostró que la mayoría de los ciudadanos sigue teniendo poco interés en la política, desconfía de las instituciones gobernantes y de representación política y está sumamente preocupada por la falta de respuestas a sus problemáticas cotidianas, lo que genera condiciones muy riesgosas para el proceso de transición política salvadoreño.

\section{Introducción}

A finales del mes de octubre de 1995, el Instituto Universitario de Opinión Pública (IUDOP) de la Universidad Centroamericana "José Simeón Cañas", bajo el auspicio de la Fundación Konrad Adenauer, realizó una investigación de opinión pública para conocer las preferencias electorales de los salvadoreños, incluyendo a las nuevas agrupaciones políticas formadas después de las elecciones de 1995.

Para comprender los resultados sobre las preferencias político-partidistas de los salvadoreños, incluyendo a las nuevas ofertas políticas expresadas en las recientes formaciones partidarias, se consi- 
deró necesario contextualizar tales resultados y leerlos a la luz de la percepción que los salvadoreños tienen acerca de su propia situación política y social. La encuesta realizada por el IUDOP no sólo exploró indicadores sobre la popularidad de los partidos en El Salvador a finales de 1995 y después de tres años de la firma de los acuerdos de paz, sino que también recogió las opiniones y valoraciones de la población salvadoreña sobre la realidad socio-política del país y sobre la manera como ésta participa en dicho proceso. El estudio en cuestión pretendió trascender el ámbito temático habitual de la opinión pública para convertirse en un elemento revelador de la percepción de la realidad social, la cual parece cuestionar estructuralmente.

A pesar de que los datos que se presentan a continuación fueron recogidos en el último trimestre de 1995, buena parte de ellos siguen siendo muy actuales, sobre todo, como reflejo de lo que piensan los salvadoreños sobre el país. Ciertamente, algunas cosas han experimentado modificaciones como las preferencias electorales y las opiniones sobre algunas figuras políticas; pero creemos, con cierto nivel de certeza, que las opiniones y actitudes hacia la realidad y hacia el sistema político no han variado sustancialmente. Es más, los sucesos que han impregnado la vida nacional en el mes de marzo de 1996, de alguna manera confirman parte de las tendencias mostradas en la encuesta, sobre todo en aquellos aspectos que señalaban la propensión y el apoyo a la institucionalización del autoritarismo.

\section{Encuesta y población encuestada}

Entre los días 21 y 28 de octubre de 1995, el Instituto Universitario de Opinión Pública (IUDOP) de la Universidad Centroamericana "José Simeón Cañas" (UCA), a pedido de la Fundación Konrad Adenauer, realizó una encuesta de opinión pública para conocer cómo evalúan los salvadoreños la situación política y económica del país, así como también indagar sobre el interés y la confianza de la población salvadoreña en la política, además de recoger las preferencias partidistas, incluidos los partidos nuevos.

El cuestionario empleado para llevar a cabo esta investigación se componía básicamente de siete partes. La primera recogía los datos demográficos de las personas: sexo, edad, escolaridad, condición de empleo y religión; además de aquella información aportada por el encuestador, referida a ciertas condiciones del entrevistado: estrato socioeconómico, departamento y municipio de residencia. La segunda parte estaba constituida por cinco preguntas que exploraban los valores que posee la población sobre diferentes ámbitos de la realidad nacional: tolerancia, conformismo, autoritarismo, etc. La sección número tres del cuestionario contenía doce preguntas referentes a la participación política de los ciudadanos: interés en la política, nivel de organización de la población, confianza en los procesos y campañas electorales, razones de la abstención en las elecciones de 1994 y nivel de participación en las próximas elecciones. El cuarto apartado constaba de quince preguntas orientadas a recoger esencialmente opiniones sobre el sistema político salvadoreño: evaluación del partido de gobierno y de los partidos de oposición, confianza en la asamblea legislativa, el presidente de la república y los partidos políticos, y evaluación de la situación política del país. La quinta parte contenía cinco preguntas con el fin de evaluar la situación económica personal y del país en la actualidad, y a la vez conocer la opinión de la población sobre el rumbo de la situación económica del país y personal dentro de un año. El sexto apartado estaba conformado por treinta y seis reactivos. En estos reactivos se recogían el conocimiento y la evaluación de los entrevistados sobre los nuevos partidos políticos, creados después de las elecciones, y sobre diferentes figuras políticas. Asimismo, este apartado recopilaba información sobre las preferencias partidistas y la definición política de los ciudadanos. El cuestionario incluyó al final tres preguntas que debían ser respondidas por el encuestador sobre la forma en la que el entrevistado respondió al cuestionario.

La muestra nacional se diseñó de tal manera que reflejase lo más fielmente posible la totalidad de la población salvadoreña; esto según los datos del censo nacional de población de 1992 y los últimos informes de la Encuesta de Hogares de Propósitos Múltiples del que fuera el Ministerio de Planificación. La cuota muestral incluyó los catorce departamentos de la república: Ahuachapán, Santa Ana y Sonsonate, por la zona occidental; La Libertad, Chalatenango, San Salvador y Cuscatlán por la zona central; Cabañas, San Vicente y La Paz por el área paracentral; y, Usulután, San Miguel, Morazán y La Unión por la zona oriental. En cada departamento se incluyeron tanto zonas urbanas como rurales. La muestra urbana se estratificó 
en cinco sectores sociales: marginal, obrero, medio bajo, medio alto y alto. La cuota rural se dejó como una categoría independiente. En el muestreo se consideraron también cuotas para los rangos de edad y el género de los encuestados.

La aplicación del cuestionario se hizo por aproximación no sistemática a los hogares ubicados en los municipios y zonas establecidas, pero definidas aleatoriamente. Los entrevistadores explicaban a las personas abordadas los objetivos y el tema de la encuesta. En cada caso se entrevistó únicamente a personas que quisieran colaborar (una persona por hogar). La muestra final obtenida fue de 1,222 encuestas válidas, con un margen de error estimado de +/- 0.04 (4 por ciento). El 48.3 por ciento de los encuestados pertenece al sexo masculino, mientras que el 51.7 por ciento corres- ponde al sexo femenino. La edad promedio es de 36.9 años con una desviación típica de 14.3 años. Los encuestados tienen un promedio de 7.2 años de estudio y poco más de la mitad de ellos se encuentra empleada en la actualidad o posee un trabajo propio.

El nivel de validez de la encuesta se obtuvo a partir de una escala construida con las respuestas a tres preguntas completadas por el encuestador al final de cada entrevista. La escala iba desde tres que significaba que la encuesta no tenía ninguna validez, hasta doce que mostraba el máximo nivel de validez del sondeo. El promedio total de validez de todas las encuestas fue de 9.47 , lo que representa un nivel aceptable. A continuación, el Cuadro 1 muestra la distribución de la población encuestada por departamento y sector social.

Cuadro 1

Distribución de la población encuestada según departamento y sector social

\begin{tabular}{|c|c|c|c|c|c|c|c|c|c|}
\hline \multirow{2}{*}{\multicolumn{2}{|c|}{ Departamento }} & \multicolumn{6}{|c|}{ Sector social } & \multicolumn{2}{|c|}{ Todos } \\
\hline & & Alto & Med-alto & Med-bajo & Obrero & Marginal & Rural & $\mathrm{N}$ & $\%$ \\
\hline \multicolumn{2}{|c|}{ Ahuachapán } & 2 & 4 & 4 & 8 & 4 & 36 & 58 & 4.7 \\
\hline \multicolumn{2}{|c|}{ Santa Ana } & 8 & 15 & 13 & 22 & 14 & 42 & 114 & 9.3 \\
\hline \multicolumn{2}{|c|}{ Sonsonate } & 4 & 10 & 10 & 15 & 10 & 36 & 85 & 7.0 \\
\hline \multicolumn{2}{|c|}{ La Libertad } & 7 & 14 & 18 & 24 & 18 & 47 & 128 & 10.5 \\
\hline \multicolumn{2}{|c|}{ Chalatenango } & 3 & 4 & 4 & 6 & 2 & 21 & 40 & 3.3 \\
\hline \multicolumn{2}{|c|}{ San Salvador } & 32 & 59 & 61 & 95 & 68 & 46 & 361 & 29.5 \\
\hline \multicolumn{2}{|c|}{ Cabañas } & 2 & 1 & 5 & 5 & 3 & 18 & 34 & 2.8 \\
\hline \multicolumn{2}{|c|}{ Cuscatlán } & 2 & 5 & 5 & 8 & 5 & 15 & 40 & 3.3 \\
\hline \multicolumn{2}{|c|}{ San Vicente } & 2 & 4 & 4 & 6 & 4 & 12 & 32 & 2.6 \\
\hline \multicolumn{2}{|c|}{ La Paz } & 3 & 8 & 8 & 12 & 8 & 20 & 59 & 4.8 \\
\hline \multicolumn{2}{|c|}{ Usulután } & 4 & 8 & 8 & 12 & 8 & 36 & 76 & 6.2 \\
\hline \multicolumn{2}{|c|}{ San Miguel } & 6 & 12 & 15 & 22 & 18 & 20 & 93 & 7.6 \\
\hline \multicolumn{2}{|c|}{ Morazán } & 2 & 4 & 6 & 5 & 5 & 24 & 46 & 3.8 \\
\hline \multicolumn{2}{|c|}{ La Unión } & 4 & 6 & 6 & 10 & 6 & 24 & 56 & 4.6 \\
\hline \multirow[t]{2}{*}{ Todos } & $\mathbf{N}$ & 81 & 154 & 167 & 250 & 173 & 397 & 1222 & - \\
\hline & $\%$ & 6.6 & 12.6 & 13.7 & 20.5 & 14.2 & 32.5 & - & 100.0 \\
\hline
\end{tabular}

\section{Los principales problemas del país}

Los resultados que se exponen en este apartado no constituyen ninguna novedad, sondeo tras sondeo, los problemas principales del país identificados por la población no parecen variar sustancial- mente; sin embargo, el interés por exponerlos nuevamente obedece a la importancia que tiene la concepción del pueblo salvadoreño de los problemas nacionales en la compresión del fenómeno político-social por el que atraviesa El Salvador, de 
cómo los problemas definidos por la población están relacionados con la imagen que tiene acerca del sistema político.

Así, el primer dato interesante del sondeo sobre el sistema político salvadoreño se refiere a lo que la población identifica como el principal problema que tiene actualmente este país centroamericano. Según el Cuadro 2, un poco más de la tercera parte de los salvadoreños -el 37.1 por ciento- identifica a la delincuencia como el principal problema de El Salvador; el 18.8 por ciento señala a la economía como un problema; el 11.2 por ciento de los encuestados se refiere a la pobreza y cerca del 9 por ciento señalan tanto al desempleo como a la corrupción respectivamente. Aunque el crimen con todas sus facetas aparece como el problema individual más citado, el conjunto de respuestas de los problemas referidos a lo económico se acerca porcentualmente a la mitad. Economía, pobreza, desempleo e inflación suman el 47.7 por ciento de las opiniones de los salvadoreños y muestra que la situación económica del país sigue siendo motivo de preocupación para los ciudadanos.

\section{Cuadro 2 \\ Principal problema del país según variables \\ (En porcentajes)}

\begin{tabular}{|c|c|c|c|c|c|c|c|c|c|}
\hline \multirow{2}{*}{ Variables } & \multicolumn{9}{|c|}{ Principal problema } \\
\hline & Crimen & Economía & Pobreza & Desempleo & Inflación & Comupción & $\begin{array}{l}\text { Inestab. } \\
\text { política }\end{array}$ & Otros & No sabe \\
\hline \multicolumn{10}{|l|}{ Estrato } \\
\hline Alto & 48.1 & 19.8 & 7.4 & 7.4 & 7.4 & 1.2 & 2.5 & 3.7 & 2.5 \\
\hline Medio-alto & 40.9 & 23.4 & 3.9 & 10.4 & 3.9 & 3.9 & 5.2 & 8.4 & 0.0 \\
\hline Medio-bajo & 32.3 & 27.5 & 7.2 & 7.8 & 6.0 & 4.2 & 2.4 & 10.8 & 1.8 \\
\hline Obrero & 38.4 & 20.0 & 14.8 & 8.8 & 8.4 & 2.0 & 1.2 & 3.6 & 2.8 \\
\hline Marginal & 32.4 & 14.5 & 9.8 & 15.0 & 11.0 & 0.6 & 2.3 & 5.9 & 8.7 \\
\hline Rural & 36.5 & 14.4 & 14.9 & 6.5 & 11.6 & 1.5 & 0.5 & 5.9 & 8.3 \\
\hline \multicolumn{10}{|l|}{ Estudios } \\
\hline Ninguno & 35.2 & 12.3 & 14.5 & 5.6 & 13.4 & 1.1 & 1.1 & 6.3 & 10.6 \\
\hline Primaria & 34.9 & 19.6 & 13.2 & 7.2 & 10.8 & 1.2 & 0.7 & 5.5 & 6.9 \\
\hline Plan básico & 44.0 & 16.1 & 6.5 & 14.9 & 8.3 & 0.0 & 0.6 & 5.4 & 4.2 \\
\hline Bachillerato & 39.6 & 20.8 & 10.8 & 5.4 & 8.8 & 3.5 & 3.1 & 7.0 & 1.2 \\
\hline Técnico & 34.0 & 16.0 & 12.0 & 12.0 & 10.0 & 0.0 & 8.0 & 8.0 & 0.0 \\
\hline Universitario & 33.6 & 25.0 & 7.1 & 10.7 & 3.6 & 7.1 & 3.6 & 7.9 & 1.4 \\
\hline \multicolumn{10}{|c|}{ Opción partidista } \\
\hline Ninguno & 34.7 & 20.1 & 12.1 & 6.7 & 8.8 & 2.1 & 2.9 & 7.9 & 4.6 \\
\hline ARENA & 44.3 & 20.1 & 8.2 & 5.7 & 7.7 & 1.0 & 1.5 & 5.0 & 6.2 \\
\hline FMLN & 28.0 & 26.0 & 12.0 & 15.3 & 8.0 & 1.3 & 2.0 & 6.7 & 0.7 \\
\hline PDC & 38.3 & 16.7 & 6.7 & 11.7 & 8.3 & 0.0 & 5.0 & 6.7 & 6.7 \\
\hline PLD & 25.0 & 25.0 & 9.4 & 18.8 & 0.0 & 6.3 & 3.1 & 12.5 & 0.0 \\
\hline Otros & 30.6 & 18.4 & 12.2 & 8.2 & 14.3 & 6.1 & 0.0 & 6.1 & 4.1 \\
\hline Voto secreto & 31.0 & 17.2 & 10.3 & 10.3 & 13.8 & 1.7 & 1.7 & 5.1 & 8.6 \\
\hline $\mathrm{Ns} / \mathrm{Nr}$ & 40.5 & 15.2 & 12.5 & 8.2 & 9.1 & 2.5 & 1.1 & 5.2 & 5.7 \\
\hline \multirow[t]{2}{*}{ Todos } & 37.1 & 18.8 & 11.2 & 8.9 & 8.8 & 2.1 & 1.9 & 6.4 & 4.9 \\
\hline & 453 & 230 & 137 & 109 & 108 & 26 & 23 & 76 & 60 \\
\hline
\end{tabular}

En su opinión, ¿cuál es el principal problema que enfrenta actualmente El Salvador? 
No obstante, la consideración sobre los problemas del país no es la misma para todos los grupos sociales salvadoreños. Los datos indican que la percepción sobre las dificultades nacionales varía en función de la pertenencia a un grupo social. De hecho, según el sondeo realizado por el IUDOP, la delincuencia aparece más citada como problema en departamentos como Sonsonate, Cabañas, San Vicente, La Paz y San Miguel; entre las mujeres y los jóvenes y entre los votantes del Partido ARENA; pero sobre todo, la delincuencia se percibe más como problema en la medida en que se asciende en la escala socioeconómica. En cambio, los problemas económicos se citan de formas muy diversas entre las distintas variables. Por ejemplo, la economía en general es vista como dificultad nacional con más frecuencia entre las clases medias que entre el resto de sectores sociales, entre los universitarios más que entre los de menor educación, entre los votantes del FMLN que entre los votantes de otros partidos; la pobreza, por el contrario, aparece como una preocupación mayor en los obreros, los campesinos y entre los analfabetas; en el caso del desempleo, éste aparece como un problema de peso entre los marginados, entre los que han estudiado hasta un nivel medio y también entre los electores del FMLN. Finalmente, las personas de menores recursos socioeconómicos, de menor nivel educativo y que no poseen un partido político de preferencia aparecen como las más preocupadas por el problema de la inflación o el alto costo de la vida.

Así, pues, en términos generales, puede decirse que los principales problemas del país son, por un lado, la delincuencia, cuyas secuelas o productos más visibles son la violencia y la inseguridad ciudadana; y por otro lado, la situación económica, en sus distintas expresiones: pobreza, inflación y desempleo. La definición de tales problemas es, en sí misma, reflejo de las preocupaciones de los salvadoreños en función de su sector social. En todo caso, estas dificultades nacionales significan un riesgo vital para la mayoría de los ciudadanos; de hecho, nadie está exento de sufrir un asalto o ser objeto de un acto delictivo con todas sus consecuencias; $y$, por otro lado, parte de los problemas planteados hacen referencia directamente a la dificultad para mantener las condiciones básicas de supervivencia en este país.

\section{Los valores}

El sondeo realizado por el IUDOP incluyó una pequeña serie de reactivos a través de los cuales se esperaban obtener ciertos valores relacionados con el ámbito político. Conformismo, tolerancia, necesidad de liderazgo y valoración del desarrollo económico sobre la libertad política constituyen los aspectos consultados por la encuesta.

Siete de cada diez salvadoreños creen que "si uno se lo propone, la situación del país puede cambiar" (ver el Cuadro 3), lo que muestra una percepción muy positiva y cierta confianza en las propias capacidades y potencialidades de los salvadoreños. Esta actitud, sin embargo, no aparece con una tendencia clara, en virtud de los sectores socioeconómicos; por ejemplo, los resultados del sondeo revelaron que en los sectores alto, medio-bajo y marginal - grupos muy dispares entre sí- se da la menor proporción de esta actitud; en cambio, en los sectores medio-alto, obrero y rural existe mayor convencimiento de que la situación del país cambiaría por la acción propia. La variable que aparentemente tiene una incidencia clara en esta postura es la edad. A medida que ésta aumenta, la actitud positiva del encuestado disminuye; en otras palabras, son los más jóvenes quienes tienen más confianza en sí mismos para promover un cambio en el país, los más viejos tienden más a la desesperanza.

Según el sondeo, no se puede afirmar que los salvadoreños sean en conjunto muy tolerantes. A pesar de que más de la mitad de la población está de acuerdo con la idea de que los homosexuales deben tener los mismos derechos que las demás personas, existe una tercera parte - nada despreciable - que está en desacuerdo con la idea anterior (ver el Cuadro 3). La consulta reveló que la actitud de tolerancia hacia los homosexuales aumenta con el nivel socioeconómico de los encuestados y, sobre todo, con los años de educación formal. Más aún, la actitud de tolerancia es menos frecuente cuando se refiere a un aspecto de orden político: el 39.4 por ciento de los salvadoreños no admitiría a un comunista como ministro de salud frente a un 35.8 por ciento que sí lo haría (ver el Cuadro 3). Ello mostraría una marcada división entre los salvadoreños sobre este tema y una aún incipiente tolerancia política. En este caso, la tolerancia hacia un comunista estaría directamente relacionada con el nivel de estudios de la persona encuestada y con la pertenencia a una determinada agrupación política. Al igual que la tolerancia hacia los homosexuales, la actitud posi- 
tiva hacia un ministro de salud de extracción comunista aumentaría decididamente con los años de formación académica y en los partidos considerados de izquierda como el FMLN y Convergencia Democrática. En todo caso, los reactivos sobre tolerancia indicarían que en la sociedad salvadoreña existen actitudes muy enraizadas que responden a una concepción social relativamente cerrada e intransigente y, en ciertos sectores, muy discriminatoria respecto a algunos comportamientos y valores diferentes, especialmente cuando se trata de aspectos políticos.

Un dato muy ilustrativo que ofrece la presente encuesta es el que se refiere al porcentaje de salvadoreños que prefiere el desarrollo económico antes que la libertad política. El mismo Cuadro 3 indica que más de la mitad de los consultados elige el desarrollo económico sobre la libertad política. Esta postura, más frecuente entre las personas de los sectores medio-bajos, entre las mujeres, entre los menos educados y entre los votantes potenciales de ARENA, mostraría que la mayoría, sobre todo aquellos que no gozan de mayores ventajas sociales, estaría más interesada en su situación económica personal que en la posibilidad de contar con libertades políticas. Todo lo anterior indicaría, en cierta medida, la fragilidad de un sistema que, a pesar de ofrecer garantías políticas, no es capaz de generar suficiente desarrollo económico para bien de la población.

Finalmente, en lo que se refiere a opiniones relacionadas con los valores, la encuesta reveló que tres de cada cuatro salvadoreños opinan que en El Salvador hace falta un hombre fuerte y decidido que ponga orden. Este criterio se encuentra con mayor frecuencia entre las personas de menores recursos económicos, entre los más jóvenes, entre las personas de menor educación y entre los potenciales electores del Partido Demócrata Cristiano y ARENA. De nuevo se puede ver que, exceptuando los votantes de ARENA, las personas que sostienen con mayor frecuencia esta postura son aquéllas con menos recursos o ventajas socioeconómicas. En otras palabras, son las mayorías las que estarían pidiendo la presencia de una persona con rasgos que pueden lindar en lo autoritario pára dirigir el país. Esto no quiere decir, desde ningún punto de vista, que los encuestados están apelando a la presencia de los militares en el gobierno; la forma en que está redactada la pregunta no ofrece la oportunidad de ir más allá en el análisis y lo claro es que la petición se refiere a que una figura severa gobierne el país.

Ahora bien, todos estos resultados sobre las opiniones y los valores de buena parte de los salvadoreños habla de actitudes que no precisamente refuerzan una cultura democrática. A pesar de que los salvadoreños confían en su capacidad para cambiar las cosas, no existe la suficiente tolerancia aún en las esferas de lo político; además, la necesidad de libertades políticas y, en cierto modo, de las libertades ciudadanas, no llega a sobreponerse a las urgencias de mejoras económicas; y, sobre todo, se sigue apelando más a figuras autoritarias que a sistemas colegiados de participación.

Cuadro 3

Valores y opiniones relacionadas con el ámbito político (En porcentajes)

\begin{tabular}{lcrrr}
\hline & & \multicolumn{2}{c}{ Opinión } \\
\cline { 3 - 5 } Enunciados & En desacuerdo & Indeciso & De acuerdo & No sabe \\
\hline Si uno se lo propone, la situación del país puede cambiar & 19.1 & 7.4 & 70.8 & 2.7 \\
Los homosexuales deberían tener mismos derechos çùe los demás & 32.2 & 5.6 & 53.7 & 8.6 \\
Lo que E.S. necesita es un hombre fuerte y decidido que ponga orden & 16.1 & 5.3 & 75.8 & 2.8 \\
El gobiemo podría tener a un comunista como ministro de salud & 39.4 & 8.8 & 35.8 & 16.0 \\
El desarrollo económico es más importante que la libertad política & 20.6 & 13.4 & 56.3 & 9.7 \\
\hline
\end{tabular}

\section{Participación política}

Para llegar a comprender cómo los salvadore- ños ven a su sistema político, el IUDOP consideró esencial revisar su nivel de participación política. 
La participación política no sólo se mide a partir de cuánto se comprometen los ciudadanos con esta actividad — votando, por ejemplo, o militando en un partido-, sino también considerando qué tanto se interesan y confían en ella. En este punto, los resultados de la encuesta fueron muy elocuentes.

Para comenzar, es necesario decir que el nivel de organización política de los salvadoreños es sumamente bajo. Según los datos del sondeo, sólo el 2 por ciento de los consultados afirmó pertenecer a algún tipo de organización política (ver la Ilustración 1). Después de la organización política sólo se encuentra la sindical; ambas ocupan los niveles más bajos de la escala. La poca organización de los salvadoreños se da en todos los niveles, con cierta excepción en el ámbito religioso, donde alcanza al 30.2 por ciento. Ahora bien, la participación en cualquier tipo de estructura aparece relacionada con la condición social de la persona. Si bien es cierto que la mayoría de los salvadoreños no se encuentra organizada, hay que reconocer que entre los sectores económica y educativamente más aventajados es posible encontrar mayores registros de organización. Esto es especialmente cierto cuando los datos se refieren a la organización gremial o profesional y a la organización política. Sin embargo, las cosas cambian cuando la estructura es de orden religioso. De acuerdo a los datos, en la medida en que se "desciende" en la escala socioeconómica, aumenta la proporción de salvadoreños que participa en una organización religiosa; asimismo, en la medida en que el grupo de consultados cuenta con un promedio menor de escolaridad, en esa medida crece el número de participantes en organizaciones religiosas. En otras palabras, las mayorías de este país, los pobres, sólo se organizan en estructuras religiosas, muy raramente lo hacen bajo agrupaciones políticas.

\section{Ilustración 1}

Tipo de organización a la que pertenecen los entrevistados

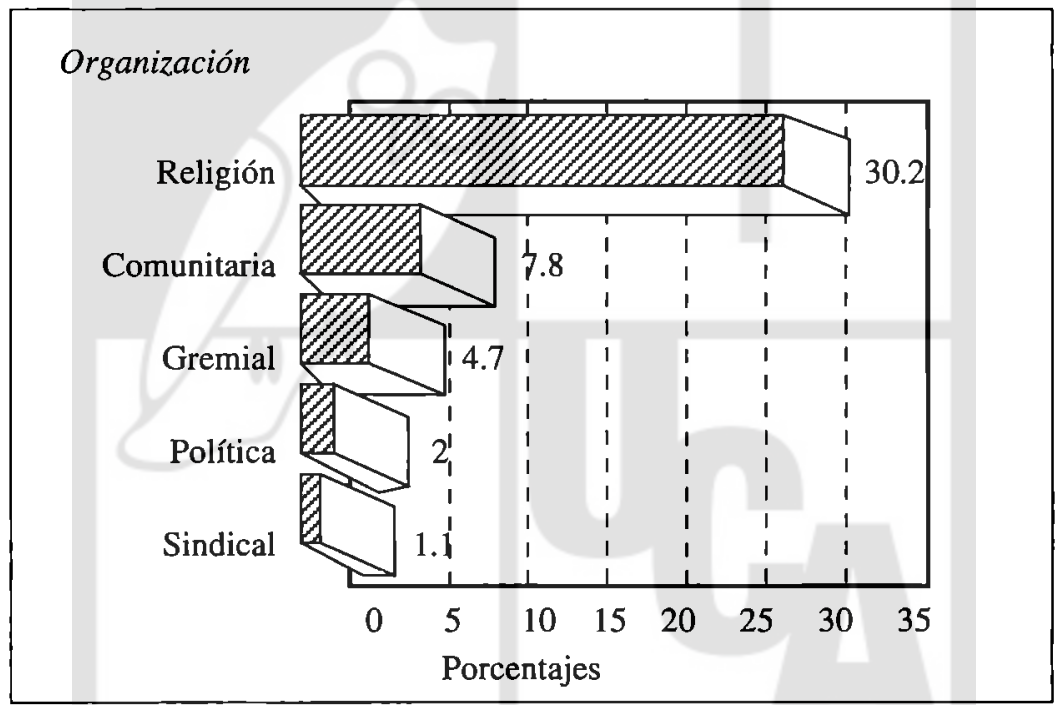

¿Es miembro Ud. de algún tipo de organización...?

De acuerdo al Cuadro 4, el interés por la política manifestado por la población es mayoritariamente nulo o escaso. De hecho, el 85 por ciento de los salvadoreños tiene poco o ningún interés en la política. El cuadro indica que el desinterés se muestra especialmente en las clases sociales más desprotegidas y en las personas con un nivel educativo limi- tado. Un dato interesante a este respecto es el que se refiere a la opción partidista: los que afirman no tener una opción partidista a la cual votar y aquéllos que no revelan su voto son quienes registran los mayores niveles de desinterés en la política salvadoreña. Por el contrario, los que dicen tener mucho interés sólo constituyen el 11.2 por ciento de los 
encuestados, predominando las personas que pertenecen a estratos acomodados y con un nivel educativo elevado; además, el interés es manifestado mucho más en los hombres que en las mujeres.

La misma tendencia se obtuvo cuando se preguntó a los salvadoreños acerca de su interés por participar directamente en un partido político. Se- gún los resultados, sólo al 15.3 por ciento de los salvadoreños le gustaría participar activamente en un partido político, el 83.1 por ciento restante afirmó que no le gustaría participar. El desinterés por pertenecer a un partido político aparece de nuevo y consistentemente entre las personas con mayores desventajas sociales y económicas.

\section{Cuadro 4}

Interés en la política según variables

(En porcentajes)

\begin{tabular}{|c|c|c|c|c|}
\hline \multirow[b]{2}{*}{ Variables } & \multicolumn{4}{|c|}{ Interés } \\
\hline & Nada & Poco & Mucho & No sabe \\
\hline \multicolumn{5}{|l|}{ Estrato } \\
\hline Alto & 39.5 & 43.2 & 16.0 & 1.2 \\
\hline Medio-alto & 31.8 & 46.8 & 20.8 & 0.6 \\
\hline Medio-bajo & 34.1 & 49.7 & 15.0 & 1.2 \\
\hline Obrero & 47.6 & 36.4 & 14.4 & 1.6 \\
\hline Marginal & 52.0 & 37.0 & 8.7 & 2.3 \\
\hline Rural & 60.5 & 28.7 & 6.3 & 4.5 \\
\hline \multicolumn{5}{|l|}{ Sexo } \\
\hline Masculino & 42.9 & 40.2 & 15.6 & 1.4 \\
\hline Femenino & 52.8 & 35.1 & 8.5 & 3.5 \\
\hline \multicolumn{5}{|l|}{ Estudios } \\
\hline Ninguno & 69.3 & 20.1 & 6.1 & 4.5 \\
\hline Primaria & 59.3 & 29.2 & 7.9 & 3.6 \\
\hline Plan básico & 47.0 & 45.2 & 6.5 & 1.2 \\
\hline Bachillerato & 38.1 & 48.5 & 12.7 & 0.8 \\
\hline Técnico & 24.0 & 56.0 & 20.0 & 0.0 \\
\hline Universitario & 16.4 & 47.1 & 34.3 & 2.1 \\
\hline \multicolumn{5}{|l|}{ Opción partidista } \\
\hline Ninguno & 62.3 & 28.9 & 6.7 & 2.1 \\
\hline ARENA & 42.3 & 40.7 & 14.4 & 2.6 \\
\hline FMLN & 27.3 & 44.0 & 26.7 & 2.0 \\
\hline PDC & 35.0 & 55.0 & 8.3 & 1.7 \\
\hline PLD & 31.3 & 46.9 & 21.9 & 0.0 \\
\hline Otros & 30.6 & 49.0 & 20.4 & 0.0 \\
\hline Voto secreto & 60.3 & 32.8 & 5.2 & 1.7 \\
\hline $\mathrm{Ns} / \mathrm{Nr}$ & 53.2 & 35.0 & 8.4 & 3.4 \\
\hline Todos & 48.0 & 37.6 & 11.9 & 2.5 \\
\hline
\end{tabular}

¿Cuánto le interesa la política? 
Todo lo anterior, es decir, los niveles de desinterés mostrados por la población, concuerda con la actitud que tendría la misma población si en la actualidad hubiese una campaña electoral. Alrededor de dos tercios de los salvadoreños estarían poco o nada interesados en un proceso electoral si éste se desarrollara en las fechas en que fue hecho el sondeo. Sin embargo, si el interés en una imaginaria campaña electoral es de por sí bajo, la confianza que los salvadoreños tendrían en la misma se revela aún inferior. Efectivamente y de acuerdo al Cuadro 6, el 67.9 por ciento de los consultados tendría poca o ninguna confianza en un proceso electoral. Curiosamente, tal desconfianza se expresa con mayor intensidad entre las personas que no identifican un partido de preferencia.

A pesar de los resultados que indican el desinterés y la desconfianza de los salvadoreños hacia aquellos aspectos relacionados con la participación política de orden electoral, el sondeo realizado por el IUDOP indicó que el 75.5 por ciento de los consultados afirmó que iría a votar si las elecciones fueran en las fechas de la encuesta. Este porcentaje es aún mayor entre aquellas personas que tienen un partido político de preferencia, pero es sensiblemente menor (el 44.8 por ciento) entre aquellos que no prefieren a partido alguno. Con todo, estos datos parecen contradecir la tendencia general mostrada en las preguntas sobre participación, interés y confianza política electoral de la población. Sin embargo, en la misma encuesta se incluyó la siguiente pregunta: ¿Cree $U d$. que muchos salvadoreños se abstendrían de votar en las próximas elecciones? Según el sondeo, el 62.4 por ciento de los consultados piensa que el resto de ciudadanos se abstendría de votar, mientras que el 20.5 por ciento opina que el resto no se abstendría de votar y el 17.1 por ciento no respondió. Estos resultados aparecen más coherentes con el resto de información obtenida en la encuesta.

¿Cómo se explica la contradicción entre dos preguntas que se refieren a lo mismo, a la conducta ante el voto? La experiencia de investigación política sugiere que cuando se interpela directamente a la población respecto a un comportamiento que es exigido institucionalmente -como el hecho de votar-, la mayoría reacciona respondiendo de manera positiva, cumpliendo con la expectativa formal; sin embargo, cuando la pregunta es formulada de forma que puede ser proyectada hacia los demás y descargada de la propia responsabilidad, los resultados varían mucho más y se acercan más a la opinión real de los encuestados. En este caso, es probable que los salvadoreños respondan con mayor veracidad cuando proyectan su intención de voto en los demás que en sí mismos.

Cuadro 5

Interés en una campaña electoral actual según sector social y opción partidista (En porcentajes)

\begin{tabular}{lccccc}
\hline Variables & \multicolumn{5}{c}{ Interés } \\
\cline { 3 - 6 } & Nada & Poco & Algo & Mucho & No responde \\
\hline Estrato & & & & & \\
Alto & 30.9 & 24.7 & 16.0 & 27.2 & 1.2 \\
Medio-alto & 24.0 & 32.5 & 17.5 & 25.3 & 0.6 \\
Medio-bajo & 28.1 & 31.1 & 19.8 & 16.8 & 4.2 \\
Obrero & 38.0 & 29.2 & 14.4 & 15.6 & 2.8 \\
Marginal & 34.7 & 26.0 & 16.8 & 19.1 & 3.5 \\
Rural & 32.2 & 28.7 & 20.4 & 14.1 & 4.5 \\
Opción partidista & & & & & \\
Ninguno & 54.8 & 25.9 & 7.1 & 9.2 & 2.9 \\
ARENA & 25.8 & 31.4 & 20.1 & 21.1 & 1.5 \\
FMLN & 20.0 & 26.0 & 19.3 & 31.3 & 3.3 \\
PDC & 21.7 & 26.7 & 25.0 & 20.0 & 6.7 \\
PLD & 18.8 & 34.4 & 21.9 & 25.0 & 0.0 \\
Otros & 20.4 & 20.4 & 22.4 & 36.7 & 0.0 \\
Voto secreto & 37.9 & 24.1 & 19.0 & 15.5 & 3.4 \\
$\quad$ Ns/Nr & 29.5 & 32.0 & 20.5 & 13.6 & 4.3 \\
\hline Todos & 32.1 & 29.0 & 17.9 & 17.8 & 3.3 \\
\hline
\end{tabular}

Si en la actualidad hubiera campaña electoral, ¿qué tanto le interesaría ésta? 
Ahora bien, el sondeo en cuestión incluyó una pregunta mediante la cual se pudieran obtener las razones del ausentismo en las pasadas elecciones salvadoreñas; observando el conjunto de resultados anteriores, tales preguntas servirían también para explicar algunos datos de la misma encuesta. De acuerdo a la información brindada por el sondeo (ver el Cuadro 7), los salvadoreños señalan la desconfianza y la falta de interés como las principales causas del ausentismo en el proceso electoral de 1994. El 31.4 por ciento piensa que los salvadoreños desconfiaron de las elecciones, el 15.9 por ciento cree que sus conciudadanos en general no creían en el proceso político, el 13.3 por ciento considera que sus compatriotas sencillamente no quisieron participar, el 10.6 por ciento identificó la existencia del miedo en los demás, mientras que cerca del 16 por ciento señaló los problemas técnicos y la falta de documentos como causas principales del ausentismo. Las razones vinculadas con la desconfianza institucional aparecen con más predominio entre los sectores ascendentes y educados de la población; en cambio, la falta de interés, expresada en la respuesta "no quisieron" se presenta en un sentido contrario: entre los salvadoreños más humildes y menos educados. Vale la pena destacar que el miedo fue dado como razón en proporciones significativas en los sectores rurales y en algunos departamentos en los que el pasado conflicto bélico se dio con mayor intensidad: Chalatenango, San Miguel y Morazán.

\section{Cuadro 6}

Confianza en una campaña electoral actual según sector social y opción partidista (En porcentajes)

\begin{tabular}{lrrrrr}
\hline & \multicolumn{5}{c}{ Confianza } \\
\cline { 2 - 6 } Variables & Nada & Poco & Algo & Mucho & No responde \\
\hline Estrato & & & & & \\
$\quad$ Alto & 32.1 & 40.7 & 17.3 & 8.6 & 1.2 \\
Medio-alto & 22.7 & 35.7 & 27.3 & 12.3 & 1.9 \\
Medio-bajo & 29.3 & 41.3 & 17.4 & 6.0 & 6.0 \\
Obrero & 37.6 & 38.0 & 12.8 & 8.4 & 3.2 \\
Marginal & 32.4 & 34.1 & 19.1 & 12.1 & 2.3 \\
Rural & 33.2 & 32.0 & 19.1 & 7.3 & 8.3 \\
& & & & & \\
Opción partidista & & & & & \\
Ninguno & 58.6 & 28.5 & 6.3 & 3.3 & 3.3 \\
ARENA & 20.6 & 37.1 & 24.2 & 16.0 & 2.1 \\
FMLN & 21.3 & 38.0 & 22.0 & 16.0 & 2.7 \\
PDC & 21.7 & 38.3 & 21.7 & 11.7 & 6.7 \\
PLD & 31.3 & 37.5 & 21.9 & 9.4 & 0.0 \\
Otros & 18.4 & 46.9 & 22.4 & 4.1 & 8.2 \\
Voto secreto & 27.6 & 36.2 & 22.4 & 8.6 & 5.2 \\
Ns/Nr & 30.0 & 36.8 & 19.8 & 6.1 & 7.3 \\
\hline Todos & 32.1 & 35.8 & 18.5 & 8.8 & 4.8 \\
\hline
\end{tabular}

Si en la actualidad hubiera campaña electoral, ¿cuánta confianza tendría Ud. en el proceso electoral? 


\section{Cuadro 7 \\ Opinión sobre la abstención de muchos salvadoreños en las elecciones de 1994 según variables \\ (En porcentajes)}

\begin{tabular}{|c|c|c|c|c|c|c|c|c|c|}
\hline \multirow[b]{2}{*}{ Variables } & \multicolumn{9}{|c|}{ Opinión } \\
\hline & $\begin{array}{l}\text { Desconfianza } \\
\text { en elecciones }\end{array}$ & $\begin{array}{c}\text { No } \\
\text { quisieron }\end{array}$ & $\begin{array}{l}\text { No creían } \\
\text { en proceso }\end{array}$ & Miedo & $\begin{array}{c}\text { Falta de } \\
\text { documentos }\end{array}$ & $\begin{array}{c}\text { Problemas } \\
\text { técnicos }\end{array}$ & $\begin{array}{l}\text { Problemas } \\
\text { personales }\end{array}$ & Otras & $\begin{array}{l}\text { No } \\
\text { sabe }\end{array}$ \\
\hline \multicolumn{10}{|l|}{ Estrato } \\
\hline Alto & 51.9 & 7.4 & 18.5 & 6.2 & 4.9 & 4.9 & 0.0 & 2.5 & 3.7 \\
\hline Medio-alto & 38.3 & 11.0 & 20.1 & 5.8 & 7.1 & 6.5 & 4.5 & 2.6 & 3.9 \\
\hline Medio-bajo & 38.9 & 7.8 & 19.8 & 9.0 & 9.6 & 7.2 & 2.4 & 1.2 & 4.2 \\
\hline Obrero & 29.6 & 10.8 & 18.8 & 8.4 & 12.0 & 9.6 & 3.2 & 2.4 & 5.2 \\
\hline Marginal & 30.1 & 12.7 & 13.9 & 6.4 & 12.1 & 8.7 & 5.8 & 1.2 & 9.2 \\
\hline Rural & 23.2 & 19.4 & 11.1 & 17.1 & 8.6 & 4.3 & 4.3 & 2.3 & 9.8 \\
\hline \multicolumn{10}{|l|}{ Estudios } \\
\hline Ninguno & 27.4 & 15.1 & 9.5 & 14.5 & 7.8 & 5.6 & 6.7 & 1.7 & 11.7 \\
\hline Primaria & 25.8 & 16.3 & 13.4 & 13.4 & 11.5 & 4.3 & 4.8 & 2.2 & 8.4 \\
\hline Plan básico & 28.6 & 16.1 & 15.5 & 10.1 & 10.7 & 11.3 & 2.4 & 0.0 & 5.4 \\
\hline Bachillerato & 35.8 & 11.9 & 19.2 & 6.5 & 10.8 & 6.2 & 1.5 & 2.3 & 5.8 \\
\hline Técnico & 40.0 & 6.0 & 22.0 & 16.0 & 2.0 & 12.0 & 0.0 & 2.0 & 0.0 \\
\hline Universitario & 44.3 & 4.3 & 23.6 & 2.9 & 5.0 & 9.3 & 3.6 & 4.3 & 2.9 \\
\hline Todos & 31.4 & 13.3 & 15.9 & 10.6 & 9.5 & 6.7. & 3.8 & 2.0 & 6.9 \\
\hline
\end{tabular}

¿Por qué cree Ud. que muchos salvadoreños se abstuvieron de votar en 1994 ?

¿Qué quiere decir toda esta información acerca de la participación política de los salvadoreños? Se puede decir que los salvadoreños no consideran la organización y la participación política como una vía aceptable para mejorar sus condiciones de vida. Parece claro que predominan la desconfianza y el desinterés de la población ante cualquier forma de participación, lo cual deteriora la capacidad de los ciudadanos para incidir en el sistema. Esto significaría que, los mecanismos de participación, sobre todo los de participación política, lejos de consolidarse y depurarse, tienden a delegitimarse. La excepción de la regla la constituye la organización religiosa. Esto se puede explicar por la tradición histórico religiosa de El Salvador y por su función "tranquilizadora" para los grupos y las clases sociales más desfavorecidas -que son los que registran los mayores índices participativos en este rubro. Por otra parte, la función que en este momento desempeñan las organizaciones religiosas de mayor crecimiento (los llamados cristianos evangélicos) no es precisamente la de incidir en las esferas de poder o en la toma de decisiones colectivas. Así, el hecho de que la organización sindical presente el más bajo índice añade el poco respaldo con el que cuentan las iniciativas sindicales como para convertirse en interlocutor válido frente al gobierno en una discusión de las políticas económicas. Esto complementa un panorama en el cual la participación de los salvadoreños en su sistema político, incluidos los mecanismos electorales, no parece responder a un espíritu de madurez democrática.

\section{Las opiniones sobre el sistema político}

La encuesta fue diseñada de tal manera que fuese posible obtener directamente la opinión de los ciudadanos sobre el sistema político. Esta parte complementa las actitudes de los salvadoreños respecto a la participación y añade algunas explicaciones a los datos del apartado anterior.

Cinco de cada diez salvadoreños son de la opinión que los procesos electorales han sido poco 
útiles para la democratización del país, dos de esos diez piensan que no han sido en absoluto útiles, mientras que otros dos de esos diez sí piensan que han sido muy útiles y uno no tiene opinión al respecto. La postura negativa se presenta con mayor intensidad entre los obreros y marginados, entre los que tienen menor instrucción y entre los votantes del FMLN y los que no tienen partido de preferencia; en el otro lado de la moneda, quienes confían en las elecciones como proceso democratizador son esencialmente las personas de clase alta, con educación superior y votantes del Partido ARENA.

\section{Ilustración 2 \\ El Salvador es o no es democrático}

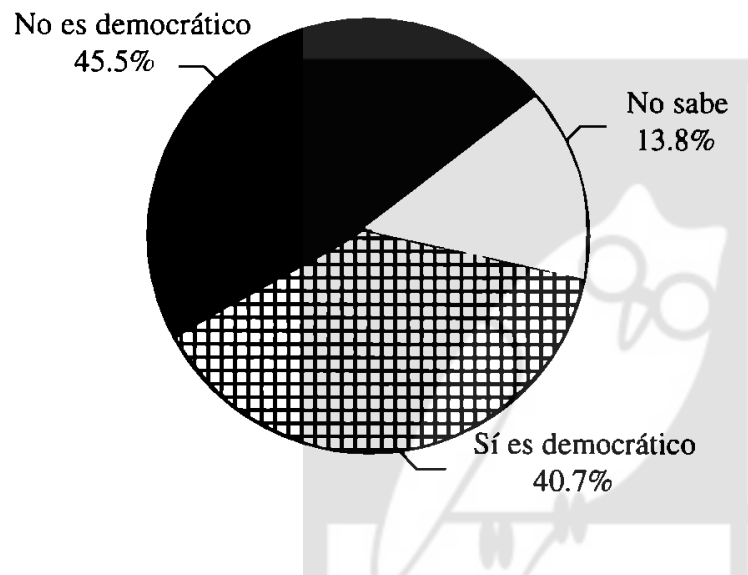

¿Cree Ud. que El Salvador es democrático o no es democrático actualmente?

La escasa legitimidad de las elecciones como base de la democracia se encuentra relacionada con el hecho de que el 45.4 por ciento de los encuestados afirmó que El Salvador no es democrático frente a un 40.7 por ciento que piensa que sí lo es (ver la Ilustración 2). Los salvadoreños con estudios superiores y sin partido de preferencia electoral, además de los votantes por el FMLN, aparecen como los sectores que más dudan acerca de la democracia en el país; en cambio, los jóvenes y los areneros son quienes defienden con mayor frecuencia la opinión sobre el carácter democrático del país.
Lo anterior también explicaría que - como revela una de las preguntas clásicas del IUDOPsólo el 4 por ciento de la población sostiene que hay que dejar el sistema social tal como está, sin cambios. Más de la mitad de la población (el 54.7 por ciento), por el otro lado, cree que son necesarias reformas y cerca de una tercera parte (el 36.7 por ciento) abogaría incluso por un cambio total de sistema, el resto no respondió. Las personas analfabetas, los votantes de izquierda y, paradójicamente, los sectores altos mantienen una posición más radical en cuanto a cambiar el sistema social; mientras que las personas de mayor edad y los electores del partido de gobierno (ARENA) se presentan como los que más defienden la permanencia del sistema tal como está.

En otro orden, el 40 por ciento de los salvadoreños considera que la situación política del país está peor después de las elecciones de 1994, el 31.5 por ciento piensa que está igual y el 21.7 por ciento sostiene que está mejor (ver el Cuadro 8). No parece haber una tendencia clara en estas opiniones respecto a los sectores socioeconómicos o respecto a los niveles educativos de los encuestados, no obstante en lo que se refiere a la preferencia partidista, es claro que las evaluaciones más pesimistas vienen de las personas que no definen su preferencia electoral y de aquellos que se constituyen en la oposición más dura del gobierno (FMLN y PLD). Estos datos reforzarían la impresión de que el sistema político salvadoreño ha venido perdiendo la firmeza que pareció lograr con la suscripción de los acuerdos de paz y su consecuente proceso político de transición.

$Y$ es que la evaluación sobre los acuerdos de paz no es tan positiva como se pudiera esperar después de tres años. Según el Cuadro 9, el 43.3 por ciento de los salvadoreños considera que los acuerdos de Chapultepec han dejado más logros que fracasos; sin embargo, un 27.3 por ciento cree que han dejado más fracasos y un 24 por ciento sostiene que han dejado tantos logros como fracasos. Tal resultado ciertamente indica que el optimismo por la paz ya no es mayoritario y, dado que la mayor opinión de reserva se da en las sectores pobres y humildes del país, se puede pensar que el desgaste viene de la falta de respuestas a los problemas que agobian a estos sectores. 


\section{Cuadro 8}

Evaluación de la situación política del país después de las elecciones de 1994 según variables (En porcentajes)

\begin{tabular}{lllll}
\hline & \multicolumn{4}{c}{ Evaluación } \\
\cline { 2 - 5 } Variables & Peor & Igual & Mejor & No sabe \\
\hline Estrato & & & & \\
Alto & 38.3 & 25.9 & 28.4 & 7.4 \\
Medio-alto & 39.0 & 31.2 & 26.0 & 3.9 \\
Medio-bajo & 36.5 & 38.9 & 20.4 & 4.2 \\
Obrero & 46.4 & 24.4 & 20.8 & 8.4 \\
Marginal & 43.4 & 30.1 & 20.8 & 5.8 \\
Rural & 37.0 & 34.8 & 20.2 & 8.1 \\
Opción partidista & & & & \\
Ninguno & 47.3 & 28.9 & 13.8 & 10.0 \\
ARENA & 32.0 & 27.8 & 32.0 & 8.2 \\
FMLN & 51.3 & 29.3 & 18.7 & 0.7 \\
PDC & 43.3 & 26.7 & 25.0 & 5.0 \\
PLD & 59.4 & 25.0 & 12.5 & 3.1 \\
Otros & 44.9 & 24.5 & 30.6 & 0.0 \\
Voto secreto & 50.0 & 29.3 & 15.5 & 5.2 \\
No sabe & 32.3 & 37.5 & 22.5 & 7.7 \\
\hline Todos & 40.1 & 31.5 & 21.7 & 6.7 \\
\hline
\end{tabular}

En su opinión, ¿la situación política salvadoreña es mejor, es igual o es peor que antes de las elecciones de 1994 ?

Cuadro 9

Evaluación de los acuerdos de paz según variables (En porcentajes)

\begin{tabular}{lllll}
\hline & \multicolumn{4}{c}{ Evaluación } \\
\cline { 2 - 5 } Variables & Más logros & Más fracasos & Es igual & No sabe \\
\hline Estrato & & & & \\
Alto & 58.0 & 19.8 & 18.5 & 3.7 \\
Medio-alto & 58.4 & 20.1 & 19.5 & 1.9 \\
Medio-bajo & 51.5 & 22.2 & 22.2 & 4.2 \\
Obrero & 39.6 & 26.8 & 29.6 & 4.0 \\
Marginal & 33.5 & 34.7 & 22.0 & 9.8 \\
Rural & 37.5 & 30.7 & 24.9 & \\
Estudio & & & & 7.8 \\
Ninguno & 30.7 & 39.1 & 22.3 & 6.5 \\
Primaria & 35.4 & 31.1 & 27.0 & 5.4 \\
Plan básico & 46.4 & 22.6 & 25.6 & 5.4 \\
Bachillerato & 49.2 & 24.2 & 21.2 & 2.1 \\
Técnico & 60.0 & 18.0 & 22.0 & \\
Universitario & 62.1 & 15.0 & 20.7 & 7.1 \\
Opción partidista & & & & 4.6 \\
Ninguno & 36.8 & 30.1 & 25.9 & 0.7 \\
ARENA & 56.7 & 23.2 & 15.5 & 1.7 \\
FMLN & 42.0 & 35.3 & 22.0 & 6.3 \\
PDC & 43.3 & 31.7 & 23.3 & 2.0 \\
PLD & 28.1 & 43.8 & 21.9 & 5.2 \\
Otros & 53.1 & 32.7 & 12.2 & 7.5 \\
Voto secreto & 39.7 & 34.5 & 20.7 & 5.5 \\
No sabe & 41.8 & 21.4 & 29.3 & 24.0 \\
\hline Todos & 43.3 & 27.3 & & \\
\hline
\end{tabular}

Evaluando la situacion del país en la actualidad, ¿cree Ud. que los Acuerdos de paz han tenido más logros o más fracasos? 
Así, para los salvadoreños, el conjunto de datos sobre el sistema político sugiere que éste no parece llenar los requisitos de legitimidad entre la población. A pesar de los procesos electorales y del logro de la paz, el sistema no llega a ser visto como suficientemente democrático y se exigen cambios, en parte, porque la población no ha logrado solucionar sus problemas básicos de supervivencia, que es lo que exige de los mismos como se muestra en otro dato de la encuesta.

¿Cómo son vistos los agentes y las instituciones del sistema político? Según los resultados de la encuesta, buena parte de los salvadoreños reconoce el papel de los partidos políticos en el logro y la consolidación de la paz -el 61.6 por ciento de los encuestados dijo que el papel de los partidos políticos en el logro de la paz había sido muy o algo importante, mientras que el 33.7 por ciento dijo que había sido poco o nada importante. Este rol se valora mejor entre los salvadoreños acomodados y con mayor educación que entre los de ba- jos recursos y poca instrucción. La explicación a esto podría encontrarse en un reconocimiento por parte de la población del esfuerzo realizado por los partidos para encontrar un entendimiento y poner fin a la guerra civil. Sin embargo, a la hora de evaluar el desempeño general de los partidos políticos, tanto desde la perspectiva del partido en el poder, como desde la de los partidos de la llamada oposición, las opiniones no resultan tan favorables. Realizando un promedio de las opiniones emitidas, la valoración del partido en el gobierno se situaría entre regular y mala, más cercana a regular que a mala (ver el Cuadro 10). Lógicamente, quienes mejor lo evalúan son los que votarían por ARENA si las elecciones tuvieran lugar en los días de la encuesta. Respecto al desempeño de los partidos de oposición, los salvadoreños son algo más benévolos, disminuyendo el número de los que lo consideran muy malo. La evaluación promedio se situaría entre regular y buena, viéndolos de una forma más positiva los potenciales votantes del FMLN y del Partido Demócrata Cristiano.

Cuadro 10

Evaluación sobre el desempeño del partido del gobierno y de los partidos de oposición según variables

(En porcentajes)

\begin{tabular}{lcccccc}
\hline \multirow{2}{*}{ Partidos } & \multicolumn{6}{c}{ Evaluación } \\
\cline { 2 - 7 } & Muy Bueno & Bueno & Regular & Malo & Muy malo & No sabe \\
\hline De gobierno & 2.0 & 26.3 & 30.4 & 26.4 & 10.6 & 4.4 \\
De oposición & 3.2 & 28.3 & 28.3 & 20.8 & 3.5 & 15.9 \\
\hline
\end{tabular}

¿Cómo evaluaría Ud. el desempeño actual del partido de gobierno?

¿Cómo evaluaría Ud. el desempeño actual de los partidos de la llamada oposición?

El hecho de que el partido de gobierno sea peor evaluado que el conjunto de los partidos de oposición se explicaría por la erosión a la cual se ve expuesto todo gobierno, sobre todo cuando éste adopta medidas que afectan económicamente a la población. De hecho, la misma encuesta reveló que el 57 por ciento de los consultados considera que las acciones del gobierno nunca los han beneficiado. Los partidos de oposición, por el contrario, estarían capitalizando su postura de opositores a unas políticas gubernamentales tan poco populares. $\mathrm{Y}$ es que en lo que los salvadoreños funda- mentan su evaluación de los partidos políticos tiene que ver con lo que ellos consideran su principales problemas. Según el sondeo en cuestión, la mayor parte de las expectativas de los ciudadanos en torno a los políticos están relacionadas con el ámbito económico: las respuestas de ayudar al pobre, mejorar el país y promover cambios económicos reúnen un tercio de las opiniones; aunque otra tercera parte sostuvo una opinión bastante negativa: no esperan "nada" de los políticos (ver el Cuadro 11), con lo cual se hace evidente el peso de una visión de rechazo hacia los dirigentes del país. 
Sobre los políticos como personas, la encuesta reveló, además, un profundo recelo en la población. Según otros resultados de la encuesta que no se exponen acá, casi el 70 por ciento de los consultados opina que los dirigentes políticos prometen y nunca cumplen, frente a sólo un 1.5 por ciento que sigue manteniendo la confianza en ellos. La desconfianza mayor se presenta entre los marginados, las personas de la tercera edad, los salvadoreños de mayor instrucción y los que no apoyan a partido político alguno.

\section{Cuadro 11}

\section{Lo que espera de los políticos según variables}

(En porcentajes)

\begin{tabular}{|c|c|c|c|c|c|c|c|c|c|c|}
\hline \multirow[b]{2}{*}{ Variables } & \multicolumn{10}{|c|}{ Respuesta } \\
\hline & Nada & $\begin{array}{l}\text { Ayuden } \\
\text { al pobre }\end{array}$ & $\begin{array}{l}\text { Mejoren } \\
\text { al país }\end{array}$ & $\begin{array}{l}\text { Cambios } \\
\text { económicos }\end{array}$ & $\begin{array}{l}\text { Cumplan } \\
\text { promesas }\end{array}$ & $\begin{array}{c}\text { Sean } \\
\text { honestos }\end{array}$ & $\begin{array}{l}\text { Cambios } \\
\text { sociales }\end{array}$ & $\begin{array}{c}\text { Cambios } \\
\text { personales }\end{array}$ & Otras & No sabe \\
\hline \multicolumn{11}{|l|}{ Estrato } \\
\hline Alto & 38.3 & 8.6 & 11.1 & 7.4 & 4.9 & 9.9 & 6.2 & 4.9 & 5.0 & 3.7 \\
\hline Medio-alto & 28.6 & 14.9 & 11.7 & 7.1 & 5.2 & 11.7 & 7.8 & 3.2 & 7.1 & 2.6 \\
\hline Medio-bajo & 34.1 & 5.4 & 12.0 & 9.0 & 9.6 & 6.6 & 5.4 & 4.2 & 9.6 & 4.2 \\
\hline Obrero & 35.2 & 12.8 & 8.4 & 11.6 & 4.4 & 4.4 & 2.0 & 3.2 & 7.2 & 10.8 \\
\hline Marginal & 37.0 & 13.3 & 7.5 & 9.8 & 6.4 & 4.6 & 3.5 & 0.6 & 8.1 & 9.2 \\
\hline Rural & 28.0 & 10.8 & 13.1 & 11.6 & 6.3 & 1.3 & 4.3 & 2.0 & 6.8 & 15.9 \\
\hline \multicolumn{11}{|l|}{ Estudio } \\
\hline Ninguno & 37.4 & 13.4 & 8.9 & 8.9 & 3.4 & 1.7 & 2.2 & 0.0 & 8.4 & 15.6 \\
\hline Primaria & 34.0 & 9.1 & 9.6 & 11.7 & 5.3 & 2.2 & 3.6 & 2.4 & 8.3 & 13.9 \\
\hline Plan básico & 35.7 & 10.1 & 10.1 & 11.9 & 4.8 & 4.8 & 3.0 & 1.2 & 8.4 & 10.1 \\
\hline Bachillerato & 28.1 & 10.4 & 13.8 & 9.2 & 8.1 & 7.7 & 6.2 & 3.5 & 7.7 & 5.4 \\
\hline Técnico & 28.0 & 18.0 & 10.0 & 14.0 & 12.0 & 4.0 & 6.0 & 4.0 & 0.0 & 4.0 \\
\hline Universitario & 25.7 & 15.0 & 11.4 & 5.7 & 8.6 & 13.6 & 7.9 & 7.1 & 4.3 & 0.7 \\
\hline \multicolumn{11}{|l|}{ Opción partidista } \\
\hline Ninguno & 47.7 & 9.2 & 9.2 & 7.1 & 3.8 & 4.6 & 2.9 & 1.7 & 7.5 & 6.3 \\
\hline ARENA & 30.9 & 7.7 & 15.5 & 10.8 & 4.6 & 4.6 & 6.2 & 2.1 & 7.2 & 10.3 \\
\hline FMLN & 23.3 & 15.3 & 15.3 & 15.3 & 9.3 & 6.0 & 4.7 & 4.0 & 3.4 & 3.3 \\
\hline PDC & 21.7 & 10.0 & 8.3 & 16.7 & 3.3 & 0.0 & 10.0 & 6.7 & 13.4 & 10.0 \\
\hline PLD & 18.8 & 25.0 & 0.0 & 15.6 & 12.5 & 9.4 & 6.3 & 3.1 & 3.1 & 6.3 \\
\hline Otros & 30.6 & 22.4 & 4.1 & 10.2 & 4.1 & 6.1 & 10.2 & 2.0 & 6.1 & 4.1 \\
\hline Voto secreto & 43.1 & 10.3 & 13.8 & 6.9 & 3.4 & 1.7 & 3.4 & 3.4 & 8.6 & 5.2 \\
\hline $\mathrm{Ns} / \mathrm{Nr}$ & 28.9 & 10.5 & 9.8 & 8.9 & 7.5 & 5.7 & 3.0 & 2.5 & 8.2 & 15.2 \\
\hline Todos & 32.3 & 11.2 & 10.9 & 10.1 & 6.1 & 5.0 & 4.4 & 2.7 & 7.4 & 9.8 \\
\hline
\end{tabular}

Podría decirme, ¿qué espera Ud. de los políticos?

Ahora bien, ¿qué tanto confían los salvadoreños en las instituciones relacionadas con la conducción política del país? Los datos señalan que, en general, la confianza en los partidos políticos, en la asamblea legislativa y en el presidente es también muy baja. Promediando las respuestas de los encuestados en una escala que va de 0 como indicador de ninguna confianza, hasta 3 como me- 
dida de mucha confianza, ninguna de las tres instituciones, ni los partidos ni la asamblea ni la presidencia, alcanza el nivel de poca confianza (ver la Ilustración 3). En el caso de los partidos políticos, la mayor desconfianza se da en los sectores de menores recursos y entre aquellos que no poseen un partido político de elección. En el caso de la asamblea, el recelo aparece en las clases altas y de nuevo entre quienes no votan por partido alguno; mientras que en la presidencia desconfían los obreros, las personas sin educación y los no electores.

La desconfianza que aparentemente permea todos los ámbitos del sistema político salvadoreño cuestiona al mismo sistema y refuerza la impresión de que la democracia en El Salvador no goza aún de la suficiente estabilidad para su definitiva y necesaria consolidación.

\section{Ilustracion 3 \\ Nivel de confianza en las instituciones del país (Promedios)}

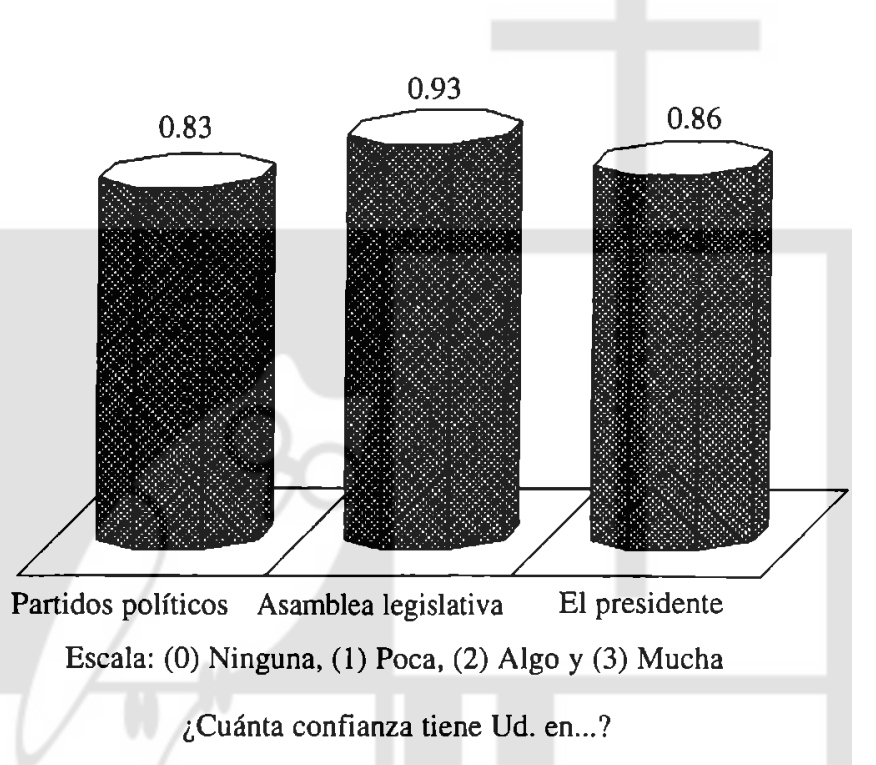

\section{Las opiniones sobre la situación económica}

En datos expuestos sobre el principal problema del país, la encuesta ha revelado la preocupación de los salvadoreños por la situación económica. Considerando la importancia que la valoración económica tiene para el ámbito político, el cuestionario básico del sondeo incluyó una pequeña batería de preguntas para obtener una impresión más precisa de cómo los salvadoreños ven sus condiciones económicas.

Lo que salta a la vista al examinar el Cuadro 12 , es que la mayoría de la población encuestada -el 61.9 por ciento - considera que la situación económica del país ha empeorado luego de la firma de los acuerdos de paz, frente un 20.6 por ciento que sostiene que sigue igual y un 15 por ciento que opina que ha mejorado. En la esfera de la economía personal, la tendencia de los resultados es parecida, aunque con menor intensidad: el 45 por ciento sostiene que está peor económicamente, el 39 por ciento afirma que su situación sigue igual y el 13 por ciento señala que está mejor (ver el Cuadro 12). En ambas valoraciones, la nacional y la personal, la proporción de personas que acusan un deterioro económico aumenta en la medida en que se desciende en la escala socioeconómica: los pobres -sobre todo si éstos no son electores del partido ARENA - perciben con mayor frecuencia que la situación económica ha empeorado. 


\section{Cuadro 12 \\ Opiniones sobre la situación económica \\ (En porcentajes)}

\begin{tabular}{lcccc}
\hline & \multicolumn{4}{c}{ Opinión } \\
\cline { 2 - 5 } Enunciados & Peor & Igual & Mejor & No sabe \\
\hline Situación económica del país después de los acuerdos de paz & 61.9 & 20.6 & 15.0 & 2.5 \\
Situación económica personal después de los acuerdos de paz & 45.1 & 39.0 & 13.8 & 2.1 \\
Situación económica del país dentro de un año & 53.9 & 14.9 & 10.1 & 21.0 \\
Situación económica personal dentro de un año & 46.7 & 20.5 & 11.1 & 21.6 \\
\end{tabular}

¿Cree Ud. que la situación económica del país está mejor, sigue igual o está peor que antes de los Acuerdos de paz?

Ahora dígame, ¿cree que la situación económica de personas como Ud. está mejor, sigue igual o está peor que antes de los acuerdos de paz?

¿Y cómo cree Ud. que será la situación económica del país dentro de un año?

¿Y cómo cree Ud. que será la situación económica de personas como Ud. dentro de un año?

Estos juicios se complementan con la opinión del 60 por ciento de los consultados de que el mayor beneficiario de las políticas económicas del gobierno son "los ricos", seguido del 19.1 por ciento que sostiene que ARENA es el grupo más beneficiado y el 9.9 por ciento que considera que todos los salvadoreños se benefician de la política económica gubernamental.

Según los resultados, la impresión general sobre la situación económica del país sigue siendo pesimista y decimos pesimista porque la misma tendencia aparece en anteriores investigaciones de opinión. Mas aún, tal actitud se encuentra también en las expectativas que los salvadoreños tienen sobre la economía. Preguntados sobre el posible estado de la economía nacional y personal dentro de un año, el 53 por ciento y el 46.7 por ciento de los encuestados afirmaron que en ambos casos estarán peor (ver el Cuadro 12).

Estos datos sugieren que la desconfianza en lo político, encontrada en la investigación, no es un fenómeno aislado. Lo económico repercute en lo político, puesto que las expectativas de la población frente a las personalidades y los procesos políticos son de orden económico, en la medida en que los salvadoreños esperan que la precariedad de sus condiciones de vida cambie. Si ello no se cumple, el sistema y todos sus componentes se deterioran ante los ojos de la población y pierden validez. En este contexto se deben entender los resultados sobre las preferencias políticas de los salvadoreños.

\section{Las preferencias políticas}

\subsection{Las preferencias por los partidos políticos}

Como era de esperarse al observar los datos que hablan sobre el sistema político, la mayoría de los salvadoreños no se identifica con ninguna agrupación política: el 61.3 por ciento de los ciudadanos no posee un partido político de preferencia según revela el Cuadro 13 . El 15.6 por ciento prefiere a ARENA, el 8.8 por ciento escoge al FMLN, el 4.9 por ciento apoya al Partido Demócrata Cristiano y el 1 por ciento prefiere al nuevo Partido Liberal Democrático. Los porcentajes restantes se dividen entre preferencias hacia otros partidos (Partido de Conciliación Nacional, Convergencia Democrática, Partido Demócrata y Movimiento de Unidad), "votos secretos" y respuestas que aducen no saber. La ausencia de preferencias partidistas se da a todos los niveles, pero especialmente en las personas de los sectores altos, en las mujeres, en las personas de mayor edad y en los ciudadanos que no cuentan con ningún nivel de estudios.

ARENA muestra tener bastante apoyo en todos los niveles, pero especialmente en la clase media-alta, entre los más jóvenes y, obviamente, entre quienes votarían por este partido si las elecciones fueran el "próximo domingo". Por su parte el FMLN es particularmente fuerte en Chalate- 
nango, La Paz y San Salvador y entre las personas con mayor educación. Las preferencias por el Partido Demócrata Cristiano se concentran en Usulután y tienden a ser de sectores medio-bajos. El Partido Liberal Democrático, uno de los parti- dos nuevos actualmente en formación, logra colarse entre los más mencionados, aunque con porcentajes bajos. Las preferencias por el Partido Liberal Democrático se concentran en los sectores altos con educación superior.

Cuadro 13

Partido político preferido según variables (En porcentajes)

\begin{tabular}{|c|c|c|c|c|c|c|c|c|}
\hline \multirow[b]{2}{*}{ Variables } & \multicolumn{8}{|c|}{ Preferencia } \\
\hline & Ninguno & ARENA & FMLN & PDC & PLD & Otros & $\begin{array}{l}\text { Voto } \\
\text { secreto }\end{array}$ & $\begin{array}{l}\text { No } \\
\text { sabe }\end{array}$ \\
\hline \multicolumn{9}{|l|}{ Estrato } \\
\hline Alto & 69.1 & 11.1 & 11.1 & 2.5 & 2.5 & 2.5 & 0.0 & 1.2 \\
\hline Medio-alto & 59.7 & 20.8 & 7.1 & 1.9 & 3.2 & 3.9 & 0.0 & 3.2 \\
\hline Medio-bajo & 61.1 & 16.8 & 7.8 & 6.6 & 1.8 & 2.4 & 0.0 & 3.6 \\
\hline Obrero & 58.8 & 13.6 & 12.8 & 5.6 & 0.8 & 3.6 & 1.2 & 3.6 \\
\hline Marginal & 59.5 & 11.6 & 11.0 & 6.4 & 0.0 & 4.6 & 0.0 & 6.9 \\
\hline Rural & 62.7 & 17.1 & 5.8 & 4.8 & 0.0 & 1.5 & 1.8 & 6.3 \\
\hline \multicolumn{9}{|l|}{ Sexo } \\
\hline Masculino & 57.1 & 16.9 & 11.0 & 3.9 & 1.2 & 4.3 & 1.0 & 4.6 \\
\hline Femenino & 65.2 & 14.4 & 6.6 & 5.9 & 0.8 & 1.6 & 0.6 & 4.9 \\
\hline \multicolumn{9}{|l|}{ Edad } \\
\hline 18 a 25 años & 57.4 & 19.6 & 9.6 & 6.7 & 0.6 & 1.9 & 0.6 & 3.5 \\
\hline 26 a 40 años & 60.1 & 15.0 & 10.1 & 4.8 & 1.3 & 3.4 & 0.8 & 4.6 \\
\hline 41 a 55 años & 66.5 & 13.5 & 6.5 & 3.7 & 0.5 & 2.8 & 0.0 & 6.5 \\
\hline 56 años y más & 66.0 & 13.0 & 6.2 & 3.7 & 0.6 & 3.1 & 2.5 & 4.9 \\
\hline \multicolumn{9}{|l|}{ Educación } \\
\hline Ninguno & 63.7 & 12.8 & 7.3 & 6.7 & 0.0 & 2.2 & 1.1 & 6.1 \\
\hline Primaria & 62.0 & 15.8 & 6.9 & 5.3 & 0.0 & 1.9 & 1.2 & 6.9 \\
\hline Plan básico & 63.7 & 13.7 & 7.1 & 6.0 & 0.6 & 2.4 & 1.8 & 4.8 \\
\hline Bachillerato & 60.4 & 18.5 & 10.4 & 3.1 & 1.5 & 3.9 & 0.0 & 2.3 \\
\hline Técnico & 56.0 & 16.0 & 10.0 & 8.0 & 4.0 & 4.0 & 0.0 & 2.0 \\
\hline Universitario & 57.1 & 15.7 & 14.3 & 2.9 & 3.6 & 5.0 & 0.0 & 1.4 \\
\hline \multicolumn{9}{|l|}{ Opción electoral } \\
\hline Ninguno & 95.0 & 2.1 & 0.0 & 1.3 & 0.0 & 0.8 & 0.0 & 0.8 \\
\hline ARENA & 35.6 & 60.3 & 1.0 & 1.0 & 0.5 & 0.5 & 0.0 & 1.0 \\
\hline FMLN & 26.0 & 5.3 & 60.0 & 4.0 & 0.0 & 2.7 & 0.0 & 2.0 \\
\hline PDC & 35.0 & 3.3 & 1.7 & 56.7 & 0.0 & 1.7 & 0.0 & 1.7 \\
\hline PLD & 50.0 & 6.3 & 0.0 & 6.3 & 31.3 & 3.1 & 0.0 & 3.1 \\
\hline Otros & 40.8 & 8.2 & 4.1 & 8.2 & 0.0 & 36.7 & 0.0 & 2.0 \\
\hline Voto secreto & 72.4 & 6.9 & 1.7 & 0.0 & 0.0 & 0.0 & 12.1 & 6.9 \\
\hline No sabe & 71.6 & 11.1 & 2.5 & 2.0 & 0.2 & 1.8 & 0.7 & 10.0 \\
\hline Todos & 61.3 & 15.6 & 8.8 & 4.9 & 1.0 & 2.8 & 0.8 & 4.7 \\
\hline
\end{tabular}

¿Cuál es su partido político de preferencia? 


\subsection{Las nuevas agrupaciones políticas}

Uno de los objetivos de la presente investigación de opinión pública era conocer precisamente la posición de las nuevas agrupaciones o partidos políticos de cara a la ciudadanía salvadoreña. Es bien sabido que después de las elecciones de 1994, los tres partidos mayoritarios han pasado por crisis, que han desembocado en la aparición de tres nuevas agrupaciones políticas; por otro lado, se han formado dos nuevas organizaciones político partidistas. Así, se pueden identificar cinco nuevas agrupaciones políticas: el Partido Liberal Democrático, el Partido Demócrata, el Partido de Renovación Social Cristiano (PRSC), el Pueblo Unido Nuevo Trato (PUNTO) y el Movimiento Auténtico Salvadoreño (MAS). Estas agrupaciones fueron evaluadas de la siguiente forma. En primer lugar, se hacía una pregunta abierta para conocer qué partidos nuevos podían ser identificados sin sugerir respuestas, es decir, qué partidos permanecen en el recuerdo fácil de la gente; luego se procedía a preguntar directamente si conocía a cada uno de los partidos nuevos y, si los reconocía, se solicitaba una evaluación en una escala de cinco puntos, donde 1 era sinónimo de pésimo y 5 era excelente. Los resultados de la evaluación se presentan en la Ilustración 4.

Ilustración 4

Evaluación de los partidos políticos nuevos (Promedios)

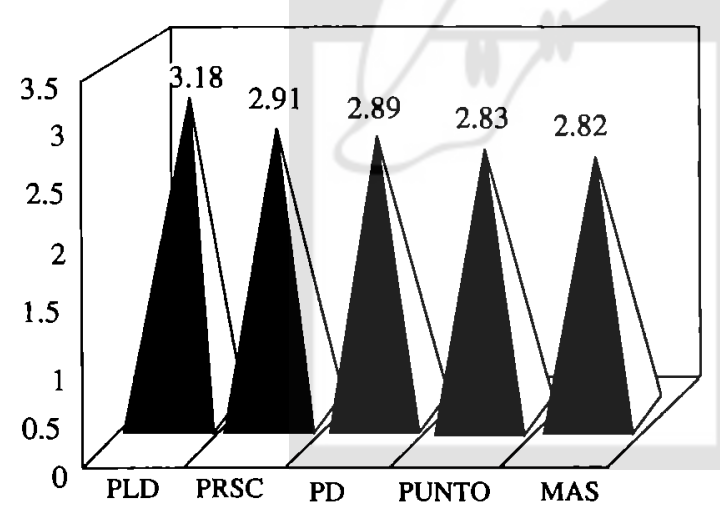

Escala: (1)Pésimo (2)Mala (3)Regular (4)Bueno (5)Excelente

$$
\text { ¿Qué opinión le merece el partido...? }
$$

La agrupación política nueva que los salvadoreños recuerdan sin ayuda con más frecuencia es el Partido Liberal Democrático (PLD), seguido a distancia por el Partido Demócrata (PD) y el Partido de Renovación Social Cristiano; los restantes dos partidós apenas son recordados por la población. Sin embargo, existe un significativo 75.7 por ciento de los consultados que no pudo recordar sin ayuda a ningún partido político nuevo. Como era de esperarse, dadas las tendencias mostradas en otros rubros, el recuerdo espontáneo es mucho menos frecuente en las áreas marginales y rurales, entre la gente con baja educación y entre los que no tienen una opción electoral clara.

Ahora bien, cuando se preguntó directamente por cada partido nuevo, los resultados cambian. El Partido Demócrata aparece con el porcentaje más alto de personas que dicen saber de él, esto es, el 47 por ciento, casi la mitad de la población; seguido del Partido Liberal Democrático con el 41 por ciento de los consultados; del Partido de Renovación Social Cristiano con el 30.9 por ciento; y el Movimiento Auténtico Salvadoreño y Pueblo Unido Nuevo Trato con el 18.5 y el 7.3 por ciento, respectivamente. Vale la pena hacer notar que las agrupaciones políticas nuevas más conocidas son aquellas que, precisamente, se separaron de otros partidos. Probablemente, el caso más polémico lo protagonizó el Partido Demócrata, el cual se separó del FMLN, y éste es, precisamente, el más conocido.

Todos los partidos políticos nuevos registran una tendencia de reconocimiento que crece en la medida en que las personas pertenecen a sectores socioeconómicos más acomodados y poseen mayor educación, lo cual quiere decir que la oferta de las nuevas agrupaciones políticas, al igual que la oferta política en general, no llega a los sectores populares, que constituyen el grueso de la población.

Sin embargo, el orden de reconocimiento de los nuevos partidos no se traduce, necesariamente, en una evaluación más o menos positiva. Según las evaluaciones de los salvadoreños de cada partido político, el Partido Liberal Democrático registra el promedio más alto. Sobre una escala de cinco puntos, este partido es el único que sobrepasa el punto medio de forma positiva, obteniendo un promedio de 3.18 entre las personas que lo conocen. Este partido es particularmente bien visto por los obreros y los campesinos, por los educados hasta plan básico y los analfabetas y por los electores del Partido Demócrata Cristiano. El siguiente partido nuevo con el mejor promedio de evaluación entre quienes lo conocen es el de Renovación Social Cristiano, que obtiene 2.91 puntos. Esta 
agrupación recoge más simpatías entre los marginados, los jóvenes, los que tienen estudios medios y entre los que votan por otros partidos. El Partido Demócrata registra 2.89 , un promedio no muy lejano del Partido de Renovación Social Cristiano, y la extracción social de sus simpatizantes es muy parecida a la de este partido: los marginados, los jóvenes y los votantes del Partido Demócrata Cristiano. Los grupos Pueblo Unido Nuevo Trato y Movimiento Auténtico Salvadoreño, los dos partidos menos conocidos, denotan también el menor promedio de evaluación, 2.83 y 2.82 respectivamente.

Con todo, los datos sugieren que las nuevas agrupaciones políticas todavía no tienen mucha presencia entre la población. Esto puede explicarse por su poco tiempo de existencia y porque el período de campaña electoral está aún lejos. Sin embargo, el hecho de que los grupos surgidos de otros partidos sean los más conocidos y mejor evaluados, establece las bases para un probable crecimiento de imagen en la esfera política salvadoreña.

\subsection{Las personalidades políticas}

En el tema de las preferencias políticas existe un aspecto que es necesario registrar para tener una idea más completa acerca de las simpatías de la población en el orden político. Esto es, las figuras o personalidades políticas. El IUDOP decidió evaluar la imagen de diez figuras políticas de actualidad, representantes de las tendencias y del pensamiento político. Estas evaluaciones se hicieron sobre una escala que iba desde 0 como la peor nota hasta 10 como la mejor.

Así, fueron escogidos Abraham Rodríguez, antiguo dirigente del Partido Demócrata Cristiano; Kirio Waldo Salgado, fundador del Partido Liberal Democrático y uno de los mayores críticos del gobierno en la actualidad; Armando Calderón Sol, presidente de la república; Joaquín Villalobos, ex dirigente guerrillero y fundador del Partido Demócrata; Mario Valiente, alcalde de la ciudad de San Salvador y miembro de ARENA; Schafik Handal, ex comandante guerrillero y dirigente del FMLN; Rubén Zamora, candidato presidencial por la coalición de izquierda en las elecciones de 1994; Alfredo Cristiani, ex presidente y dirigente del partido ARENA; Fidel Chávez Mena, candidato presidencial del Partido Demócrata Cristiano en las elecciones de 1994; y Gloria Salguero Gross, presidenta de la asamblea legislativa y dirigente de ARENA.
Las evaluaciones fueron realizadas con los consultados que dijeron conocer a cada una de las figuras o personalidades políticas. Exceptuando los casos de Abraham Rodríguez, quien, paradójicamente, en octubre de 1995 era conocido sólo por el 38 por ciento de los encuestados, a pesar de su larga trayectoria política, y de Kirio Waldo Salgado, una persona relativamente nueva en el ámbito político partidista, el resto de las personalidades evaluadas son conocidas por la mayoría de la población.

Según los datos presentados en la Ilustración 5, los notas asignadas a las personalidades políticas arrojan un promedio más bien bajo. Los promedios se mueven entre el 5.95, asignado a Cristiani, el más alto, hasta el 3.80, concedido a Gloria Salguero Gross. Esto confirmaría la tendencia de que el juicio general sobre los políticos y sus figuras más representativas no es muy bueno.

El ex presidente Cristiani es la figura mejor evaluada, seguido de Kirio Waldo Salgado. Sin embargo, existe una diferencia fundamental entre los promedios obtenidos por Cristiani y Salgado. Aunque Cristiani constituye, sin duda, la personalidad con mejor promedio, los resultados indicaron que éste atrae también muchas evaluaciones negativas (representadas en las notas de 0 a 3); ello implica una dispersión bastante amplia en la visión predominante sobre el ex presidente y revela un fenómeno de polarización en las opiniones: Cristiani es muy admirado, pero al mismo tiempo es muy rechazado. Por lo tanto, sus posibilidades de crecimiento de imagen son escasas. En cambio, Kirio Waldo Salgado, quien, ciertamente, no alcanza el promedio anterior, presenta una dispersión bastante reducida. Salgado no recibe notas extremas y la mayoría lo evalúa casi de la misma forma: de regular a positivo.

Aparte de Cristiani y Salgado, la evaluación de las figuras políticas sigue el siguiente orden descendente: Abraham Rodríguez, bien visto por los residentes de Ahuachapán y por los electores de los partidos minoritarios, pero curiosamente peor evaluado por los electores del Partido Demócrata Cristiano; Rubén Zamora, mejor examinado por los jóvenes, los universitarios y los electores del FMLN; Armando Calderón Sol, mejor considerado por la gente de clase media-alta, los jóvenes y los areneros. En el tramo de evaluaciones más negativas estarían Gloria Salguero Gross, Joaquín Villalobos, Mario Valiente, Fidel Chávez Mena y Schafik Handal. A excepción de Chávez Mena, el 


\section{Ilustración 5 \\ Evaluación de personalidades políticas (Promedios)}

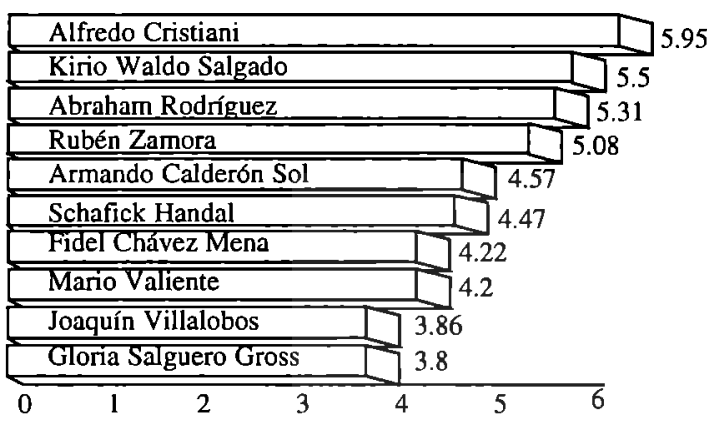

Escala: 0 a 10

¿Cómo lo calificaría de 0 a $10 ?$

resto de personalidades peor evaluadas presentan una dispersión muy alta en sus notas.

\subsection{Las opciones electorales}

Si las elecciones hubiesen sido "algún domingo" de octubre de 1995 , el 19.6 por ciento de los salvadoreños no votaría por partido alguno, el 36 por ciento no sabe por quién votaría y el 4.7 por ciento esconde su elección, con lo cual sólo el 39.7 por ciento de los encuestados definió su predilección en el sondeo. Así, siguiendo el mismo orden mostrado en las preferencias de partido, el 15.9 por ciento votaría por ARENA, el 12.3 por ciento elegiría al FMLN, el 4.9 escogería al Partido Demócrata Cristiano, el 2.6 sufragaría en favor del Partido Liberal Democrático y el 4 por ciento restante se repartiría entre la Convergencia Democrática, el Partido de Conciliación Nacional, el Movimiento de Unidad y el Partido Demócrata.

Comparando estos resultados con los de la preferencia partidista (Cuadro 13) se puede advertir que la respuesta "ninguno" disminuye y sube la de "no sabe"; además el FMLN registra un significativo aumento en las respuestas de elección. Este fenómeno, aparte del Partido Liberal Democrático, no se da en otros partidos.
Pero más significativa es la diferencia que resulta de la comparación entre la intención de voto en la actualidad y la intención de voto de quienes votaron en las elecciones de 1994 (ver el Cuadro 15). Según esta comparación, todos los partidos obtendrían porcentajes menores de elección si los comicios tuvieran lugar ahora, sobre todo ARENA, que revela un desgaste muy sensitivo. Es más, comparando las intenciones de voto en los distintos grupos sociales, ARENA estaría sufriendo su mayor desgaste en los sectores socioeconómicamente altos y en la zona rural; estos grupos estarían engrosando las filas de las personas que no votarían por ningún partido en este momento. En cambio, el FMLN perdería apoyo en el departamento de San Salvador, su bastión en las elecciones de 1994, y mantendría cierto potencial en algunos departamentos del interior del país.

Todos estos datos que hablan sobre las preferencias partidistas y las opciones electorales muestran algunas cosas en común, que ayudan a entender el panorama político de El Salvador a finales del año pasado. Este análisis tiene la ventaja de no estar contaminado con la campaña y el ambiente electoral. En primer lugar, la mayoría de los salvadoreños no haría uso de la oferta partidista. Más de la mitad de la población no prefiere a ningún partido, no votaría y no se siente identificada con una corriente política específica. Esta actitud es una consecuencia y tambien determinante de la poca credibilidad en el sistema político. En segundo lugar, las ofertas partidistas con posibilidad polarizan el sistema político salvadoreño. A pesar de que una tercera parte de la población buscaría el centro político, en realidad, las opciones viables, según el apoyo de la ciudadanía, no se encuentran en el centro, sino a la derecha y la izquierda. Esto se explica porque aparentemente no existía, a finales de 1995, una opción viable de centro. Esto refuerza la apatía de algunos electores potenciales. En tercer lugar, las nuevas agrupaciones políticas que buscan abiertamente el centro político estarían siendo afectadas por el fenómeno de la polarización. Sin embargo, el Partido Liberal Democrático parecía, en octubre y noviembre de 1995, estar rompiendo con la polarización para su provecho al mostrarse como una opción de fuera del cuestionado sistema político y al adoptar una posición crítica dura frente al gobierno sin vincularse en absoluto con la izquierda. 


\section{Cuadro 14}

Intención de voto en octubre de 1995 según variables

(En porcentajes)

\begin{tabular}{|c|c|c|c|c|c|c|c|c|c|c|}
\hline \multirow[b]{2}{*}{ Variables } & \multicolumn{9}{|c|}{ Partido político } & \multirow[b]{2}{*}{$\begin{array}{l}\text { No } \\
\text { sabe }\end{array}$} \\
\hline & Ninguno & ARENA & FMLN & PDC & $\mathrm{CD}$ & PCN & PLD & Otros & $\begin{array}{l}\text { Voto } \\
\text { secreto }\end{array}$ & \\
\hline \multicolumn{11}{|l|}{ Estrato } \\
\hline Alto & 23.5 & 14.8 & 16.0 & 0.0 & 4.9 & 1.2 & 3.7 & 4.9 & 2.5 & 28.4 \\
\hline Medio-alto & 27.3 & 21.4 & 9.1 & 3.2 & 1.3 & 0.6 & 4.5 & 2.5 & 3.2 & 26.6 \\
\hline Medio-bajo & 22.2 & 13.8 & 14.4 & 6.0 & 0.0 & 2.4 & 5.4 & 0.6 & 1.8 & 33.5 \\
\hline Obrero & 22.0 & 14.4 & 16.0 & 6.0 & 0.8 & 0.8 & 3.2 & 2.0 & 4.0 & 30.8 \\
\hline Marginal & 15.6 & 13.3 & 14.5 & 7.5 & 3.5 & 0.6 & 0.6 & 1.2 & 6.9 & 36.4 \\
\hline Rural & 14.9 & 16.9 & 8.6 & 4.3 & 0.8 & 1.0 & 1.0 & 0.9 & 6.5 & 45.3 \\
\hline \multicolumn{11}{|l|}{ Sexo } \\
\hline Masculino & 16.3 & 15.1 & 15.8 & 3.9 & 1.9 & 1.0 & 3.1 & 2.4 & 5.6 & 35.1 \\
\hline Femenino & 22.6 & 16.6 & 9.0 & 5.9 & 0.9 & 1.1 & 2.2 & 0.9 & 4.0 & 36.9 \\
\hline \multicolumn{11}{|l|}{ Edad } \\
\hline 18 a 25 años & 16.3 & 18.9 & 13.8 & 6.7 & 1.3 & 0.3 & 2.2 & 1.9 & 2.9 & 35.6 \\
\hline 26 a 40 años & 20.7 & 14.6 & 12.9 & 4.4 & 1.7 & 1.5 & 2.9 & 1.2 & 6.1 & 34.0 \\
\hline 41 a 55 años & 24.2 & 13.5 & 11.2 & 4.2 & 1.9 & 0.5 & 2.3 & 2.3 & 2.3 & 37.7 \\
\hline 56 años y más & 16.7 & 16.0 & 9.3 & 4.3 & 0.0 & 1.9 & 2.5 & 1.2 & 6.2 & 42.0 \\
\hline \multicolumn{11}{|l|}{ Educación } \\
\hline Ninguno & 16.8 & 11.7 & 11.2 & 3.9 & 0.6 & 1.1 & 0.0 & 1.2 & 8.4 & 45.3 \\
\hline Primaria & 17.7 & 18.7 & 9.6 & 6.9 & 1.0 & 1.9 & 1.2 & 0.9 & 5.0 & 37.1 \\
\hline Plan básico & 20.2 & 11.9 & 12.5 & 4.2 & 0.6 & 0.6 & 3.0 & 0.0 & 4.8 & 42.3 \\
\hline Bachillerato & 22.3 & 18.1 & 13.1 & 4.6 & 1.5 & 0.4 & 3.8 & 2.7 & 3.1 & 30.4 \\
\hline Técnico & 28.0 & 8.0 & 14.0 & 4.0 & 4.0 & 0.0 & 6.0 & 0.0 & 2.0 & 34.0 \\
\hline Universitario & 19.3 & 15.7 & 19.3 & 2.1 & 3.6 & 0.7 & 6.4 & 4.3 & 2.9 & 25.7 \\
\hline Todos & 19.6 & 15.9 & 12.3 & 4.9 & 1.4 & 1.1 & 2.6 & 1.6 & 4.7 & 36.0 \\
\hline
\end{tabular}

Si las elecciones fueran el próximo domingo, ¿por cuál partido votaría Usted? 
Cuadro 15

Partido por el que votó en las elecciones para diputados de 1994 según variables

(En porcentajes)

\begin{tabular}{|c|c|c|c|c|c|c|c|c|c|}
\hline \multirow[b]{2}{*}{ Variables } & \multicolumn{9}{|c|}{ Preferencia } \\
\hline & Ninguno & ARENA & FMLN & PDC & $\mathrm{CD}$ & PCN & Otros & $\begin{array}{l}\text { Voto } \\
\text { secreto }\end{array}$ & $\begin{array}{l}\text { No } \\
\text { sabe }\end{array}$ \\
\hline \multicolumn{10}{|l|}{ Estrato } \\
\hline Alto & 1.8 & 49.1 & 17.5 & 8.8 & 3.5 & 1.8 & 1.8 & 3.5 & 12.3 \\
\hline Medio-alto & 4.1 & 44.6 & 16.5 & 7.4 & 3.3 & 4.1 & 1.6 & 5.0 & 13.2 \\
\hline Medio-bajo & 4.4 & 35.1 & 21.9 & 13.2 & 0.9 & 2.6 & 0.9 & 6.1 & 14.9 \\
\hline Obrero & 5.6 & 36.0 & 18.0 & 7.5 & 2.5 & 2.5 & 1.2 & 7.5 & 19.3 \\
\hline Marginal & 5.6 & 29.0 & 20.6 & 10.3 & 5.6 & 0.0 & 2.8 & 9.3 & 16.8 \\
\hline Rural & 7.7 & 46.8 & 9.3 & 10.1 & 1.2 & 1.6 & 0.4 & 7.3 & 15.7 \\
\hline \multicolumn{10}{|l|}{ Sexo } \\
\hline Masculino & 5.5 & 39.8 & 19.7 & 5.7 & 4.5 & 2.5 & 1.2 & 6.2 & 14.9 \\
\hline Femenino & 5.7 & 41.1 & 12.3 & 13.3 & 0.5 & 1.7 & 1.2 & 7.4 & 16.7 \\
\hline \multicolumn{10}{|l|}{ Edad } \\
\hline 18 a 25 años & 5.7 & 41.8 & 16.3 & 11.3 & 2.1 & 2.1 & 0.7 & 5.7 & 14.2 \\
\hline 26 a 40 años & 7.2 & 39.6 & 18.6 & 9.3 & 2.7 & 1.6 & 1.1 & 5.9 & 14.1 \\
\hline 41 a 55 años & 3.8 & 36.9 & 12.1 & 9.6 & 4.5 & 1.9 & 1.8 & 8.3 & 21.0 \\
\hline 56 años y más & 1.6 & 46.1 & 13.3 & 8.6 & 0.0 & 3.9 & 1.6 & 8.6 & 16.4 \\
\hline \multicolumn{10}{|l|}{ Educación } \\
\hline Ninguno & 2.6 & 41.9 & 6.8 & 15.4 & 0.0 & 0.9 & 0.9 & 12.8 & 18.8 \\
\hline Primaria & 6.2 & 42.5 & 10.2 & 9.1 & 2.2 & 2.9 & 1.9 & 6.2 & 18.9 \\
\hline Plan básico & 13.3 & 31.1 & 15.6 & 12.2 & 0.0 & 2.2 & 0.0 & 6.7 & 18.9 \\
\hline Bachillerato & 5.6 & 1.0 & 19.9 & 8.1 & 2.5 & 1.9 & 1.2 & 6.2 & 13.7 \\
\hline Técnico & 2.3 & 31.8 & 29.5 & 13.6 & 4.5 & 2.3 & 0.0 & 2.3 & 13.6 \\
\hline Universitario & 1.7 & 42.6 & 28.7 & 3.5 & 7.0 & 1.7 & 1.8 & 5.2 & 7.8 \\
\hline \multicolumn{10}{|l|}{ Opción partidista } \\
\hline Ninguno & 15.7 & 40.9 & 9.6 & 5.2 & 3.5 & 0.9 & 0.9 & 13.0 & 10.4 \\
\hline ARENA & 1.4 & 90.3 & 0.0 & 2.8 & 0.0 & 1.4 & 0.7 & 1.4 & 2.1 \\
\hline FMLN & 0.9 & 11.6 & 70.5 & 4.5 & 5.4 & 0.0 & 1.8 & 0.0 & 5.4 \\
\hline PDC & 0.0 & 7.3 & 7.3 & 80.5 & 0.0 & 0.0 & 0.0 & 0.0 & 4.9 \\
\hline PLD & 4.0 & 52.0 & 28.0 & 4.0 & 4.0 & 0.0 & 0.0 & 0.0 & 8.0 \\
\hline Otros & 2.7 & 16.2 & 16.2 & 13.5 & 18.9 & 16.2 & 5.4 & 2.7 & 8.1 \\
\hline Voto secreto & 7.3 & 14.6 & 7.3 & 2.4 & 0.0 & 0.0 & 0.0 & 56.1 & 12.2 \\
\hline No responde & 6.5 & 37.0 & 6.8 & 7.5 & 0.7 & 2.7 & 1.4 & 4.8 & 32.5 \\
\hline Todos & 5.5 & 40.3 & 16.0 & 9.6 & 2.5 & 2.1 & 1.2 & 6.9 & 16.0 \\
\hline$N$ & 44 & 323 & 128 & 77 & 20 & 17 & 10 & 55 & 128 \\
\hline
\end{tabular}

¿Por qué partido votó Ud. en las elecciones para diputados de 1994 ? 


\section{Conclusiones}

De acuerdo a los resultados del sondeo, la opinión sobre la realidad salvadoreña en octubre de 1995 se presenta de manera poco optimista y se puede caracterizar por los siguientes aspectos. Una evaluación negativa de la situación general del país, una falta de participación política de significativos sectores de la población, una creciente pérdida de confianza en la institucionalidad política del país y una continua polarización de las posiciones políticas viables.

En primer lugar, existe un consenso generalizado de que el país no va por buen camino y que su sistema social necesita cambios. Esta impresión se concreta y refuerza en la percepción de que los principales problemas del país siguen siendo los mismos, pues no han podido ser resueltos, a pesar del proceso pacificador. Estos son, la delincuencia y la situación económica. A pesar de los esfuerzos por controlar la ola delincuencial que abate al país después del fin de la guerra, los salvadoreños no ven una mejora en términos de seguridad ciudadana. A esto se suma la percepción sobre el problema económico, que se manifiesta en la preocupación por el desempleo, la pobreza y la inflación. La mayoría de los salvadoreños, sobre todo los más pobres, considera que tanto su situación económica personal como la del país no han mejorado desde la firma de los acuerdos de paz, sino que, al contrario, han empeorado. Así, esos problemas introducen un estado de emergencia vital perpetuo, porque atentan contra la supervivencia cotidiana de los ciudadanos y estimulan una actitud de apatía ante cualquier iniciativa que no resuelva directamente dichos problemas.

Esto plantea el segundo aspecto que revela la encuesta sobre la realidad social. Dado que los problemas fundamentales no han sido resueltos, a pesar de los procesos electorales y de la firma de los acuerdos de paz, sino que, por el contrario, parecen haber empeorado, la mayoría de los salvadoreños desconfía de manera creciente de la participación política como un medio para incidir en la situación del país. De hecho, la intervención de la ciudadanía salvadoreña en cualquier tipo de organización, no sólo la política, es poca. Exceptuando una tendencia a participar en grupos religiosos de carácter fundamentalista, que al mismo tiempo bloquea la participación en la actividad política, los salvadoreños raramente hacen uso de canales colectivos de incidencia social para expresar sus inquietudes o defender sus intereses de grupo.

En tercer lugar, existe un significativo desinterés y una profunda desconfianza de la población frente a lo político y todo aquello que se relacione con ello. Los salvadoreños no sólo no se organizan políticamente, sino que ven los procesos electorales con poco interés, a los políticos con poca credibilidad y a las instituciones gobernantes - la asamblea legislativa y el poder ejecutivo- con una marcada desconfianza. Esto se traduce en una creciente pérdida de legitimidad del sistema a los ojos de los ciudadanos. Más aún, la población no parece estar convencida de que el sistema político salvadoreño sea democrático. Aparentemente, los salvadoreños cuestionan la institucionalización de la democracia y el carácter democrático de los procesos electorales, promovidos por el actual sistema político, no tanto por su falta de libertades o garantías políticas, sino por la incapacidad del sistema para asegurar un desarrollo económico que resuelva sus dificultades concretas, lo cual a su vez refuerza la impresión de que el sistema social necesita cambios y debilita su estabilidad al exponerlo a opciones autoritarias, que se presenten como capaces de dar respuesta a la crisis económica. Desde esta perspectiva se explica que, a pesar de los cambios institucionales, la mayoría de la población apoya la figura de una persona "fuerte y decidida que ponga orden" y antepone el desarrollo económico a la libertad política.

En cuarto lugar, la realidad política salvadoreña presenta un marcado fenómeno de polarización entre aquellos ciudadanos que sí participan políticamente. Los datos sugieren que el segmento de la población más comprometido políticamente tiende a mostrarse profundamente dividido en opiniones y valores, sobre todo cuando éstos se refieren al régimen, al partido de gobierno, al partido de la izquierda o a las figuras más representativas de esos institutos. Esta polarización permea la percepción de la realidad del país y somete sus valoraciones a un esquema maniqueísta, que dificulta las actitudes de tolerancia, necesarias para el diálogo democrático. Este fenómeno debilita las posturas intermedias y estabilizadoras y obliga a los ciudadanos a definirse por los partidos que representan los polos del sistema político. En estas circunstancias, se explica que buena parte de la población prefiera mantenerse al margen de la actividad política, pues no piensa tener una opción viable alternativa, y surgen posibilidades reales para 
el surgimiento de una figura que provenga de fuera del sistema político.

Como corolario hemos de agregar que mucho de lo que está pasando actualmente en la realidad nacional, a finales del mes de marzo, signada por la histeria de la violencia y la delincuencia y por el surgimiento formal e institucional de medidas drásticas - que rayan en el autoritarismo-, tiene mucho que ver con la situación del sistema político adelantado por la encuesta de octubre.

\section{Referencias bibliográficas}

Instituto Universitario de Opinión Pública. (1995). Encuesta sobre el sistema politico salvadoreño. Serie de informes 51. San Salvador: UCA. 